\title{
CASE STUDY OF SOUTHWESTERN WISCONSIN CONFERENCE HIGH SCHOOL DIVERSITY CLUBS: \\ ADVISOR QUALIFICATIONS, CLUB RESOURCES, AND MULTICULTURAL CURRICULUM
}

\author{
A Dissertation \\ presented to \\ the Faculty of the Graduate School \\ at the University of Missouri-Columbia \\ In Partial Fulfillment \\ of the Requirements for the Degree \\ Doctor of Education \\ by \\ BRITTANY LYNN PARRY \\ Dr. Jeffrey Cornelius-White, Dissertation Supervisor \\ MAY 2018
}


(C) Copyright by Brittany Cox Parry 2018

All rights reserved 
The undersigned, appointed by the dean of the Graduate School, have examined the dissertation entitled

\section{CASE STUDY OF SOUTHWESTERN WISCONSIN CONFERENCE HIGH SCHOOL DIVERSITY CLUBS: \\ ADVISOR QUALIFICATIONS, CLUB RESOURCES, AND \\ MULTICULTURAL CURRICULUM}

presented by Brittany Parry,

a candidate for the degree of doctor of education,

and hereby certify that, in their opinion, is worthy of acceptance.

Dr. Jeffrey Cornelius-White

Dr. Cynthia MacGregor

Dr. Patricia Wall

Dr. Jon Turner 


\section{DEDICATION}

I dedicate this dissertation to the following:

God, my Peacemaker,

I credit my Creator who exemplifies the power of embracing those different than ourselves.

Caleb Parry, my husband, since we were 16-years-old you have supported every aspiration I have had. You provide me with endless love and encouragement (and pancakes). You are a man of great integrity who truly values my thoughts, dreams, and independence. I love you \#goteamparry

Dave and Frances Cox, my parents,

thank you for providing steadfast encouragement and allowing me to grow into an independent woman with independent thoughts. You always trusted me to make the right decisions and offered me fearless faith. This dissertation is a testament to your love for your children and the love for education you instilled in us.

PawPaw and MawMaw, my grandparents, you often tell me of an early birthday where I received countless toys and you gifted me books. You said I opted for the books and spent my birthday attempting to read, although I had not yet learned the alphabet. Your pride in my education and faith in God have impacted so many of my life decisions. Thank you for being such amazing grandparents.

MeeMaw and PeePaw, my grandmother and late grandfather, you have kept newspaper clippings of your grandchildren's' successes for as long as I can remember. Your love for us was always transparent. It was not uncommon for PeePaw to grab an encyclopedia mid-sentence to look up a random fact. Your search for knowledge was contagious.

Ashley and Drew Alexander, and David Cox, my siblings and brother-in-law, thank you for always making me laugh, pushing me out of my comfort zone, and being willing to be weird with me.

Jo Lynn and Wayne Parry, Sarah, Rachel, and Leah, my family-in-law, from the time I came into your family you made me feel loved and valued. Thank you for your prayers and kind words during this process.

friends and family members, thank you for encouraging and loving me.

my colleagues and former students, thank you for providing me with daily reminders of why I love my job. 


\section{ACKNOWLEDGEMENTS}

I would like to formally thank the members of my dissertation committee: Dr. Cynthia MacGregor, Dr. T.C. Wall, and Dr. Jon Turner. I truly appreciate the time they spent revising my copious drafts, and their words of wisdom. Each committee member encouraged me and provided honest feedback, making me a stronger writer. I would also like to acknowledge and express gratitude for my advisor, Dr. Jeffrey Cornelius-White. He has been understanding of my long-distance learning, provided me with encouragement, and offered alternative ways of thinking that strengthened my research and my skills as a researcher.

I would also like to acknowledge the members of Cohort 10. Your strengths as educational leaders provided me with new goals of what type of leader I hoped to become. Your contributions to class discussions and personal interest in my own growth created a group dynamic I am very thankful for. Stacy Hagston, Christi Sudbrock, and Kerri Cox, thank you for your friendship and encouragement through various life changes. 


\section{TABLE OF CONTENTS}

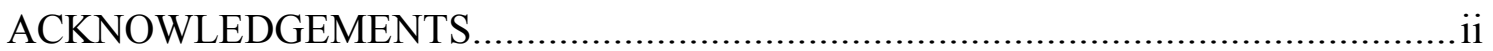

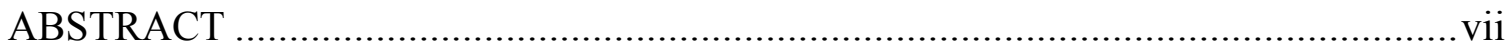

Chapter

I. INTRODUCTION TO DISSERTATION .............................................. 1

Statement of Problem ................................................................ 4

Purpose of Study ........................................................................... 6

Research Questions .............................................................. 8

Conceptual Framework ................................................................ 8

Banks Multicultural Education Theory............................................... 8

Bass Transformational Leadership Theory............................11

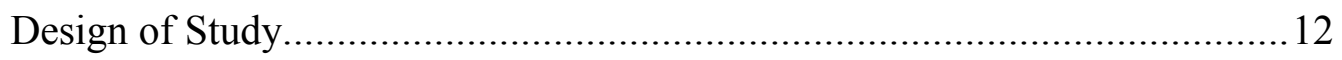

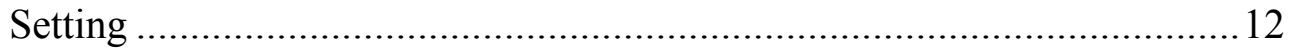

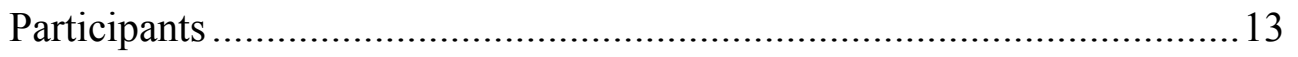

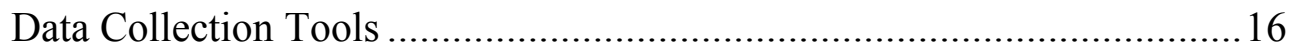

Data Analysis.................................................................................. 19

Limitations, Assumptions, and Design Controls....................................20

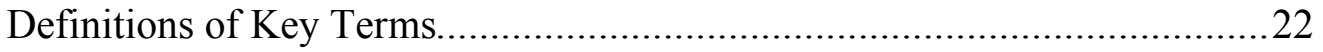

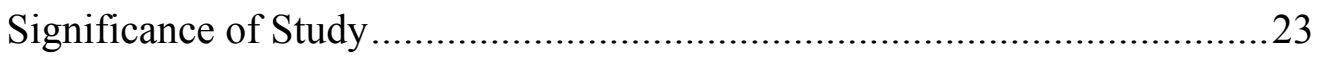

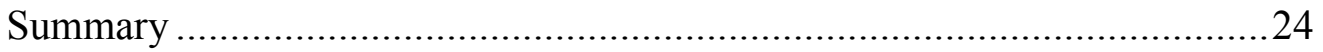

II. PRACTITIONER SETTING FOR THE STUDY ....................................26

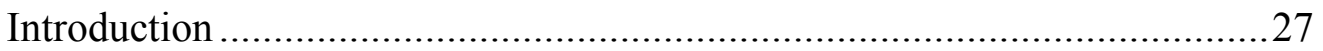

History of Organization .................................................................2 27 


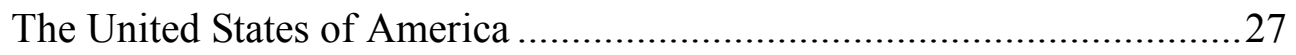

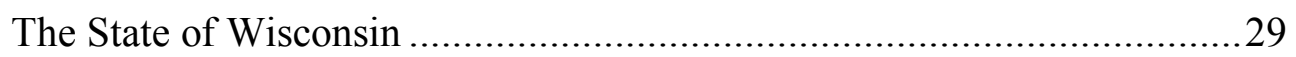

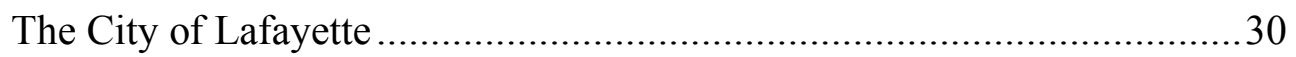

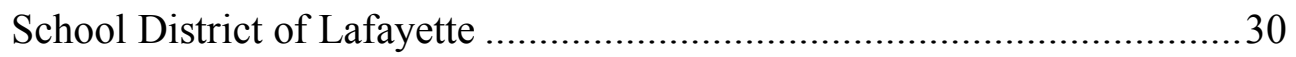

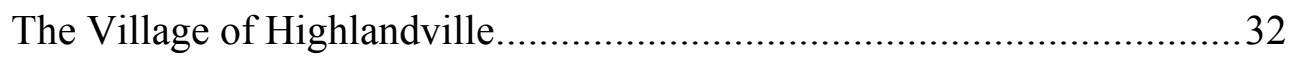

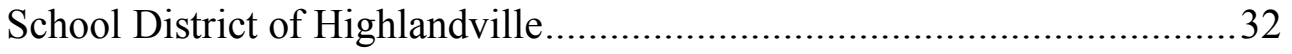

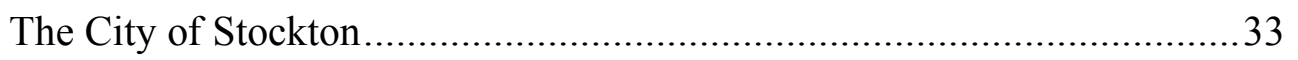

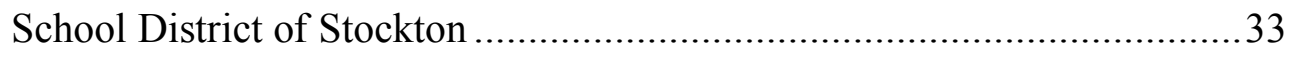

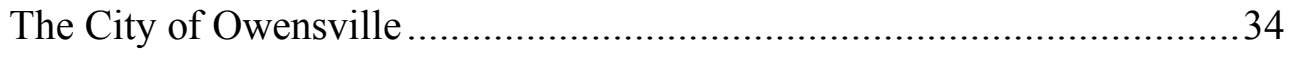

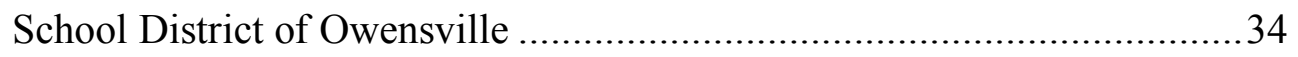

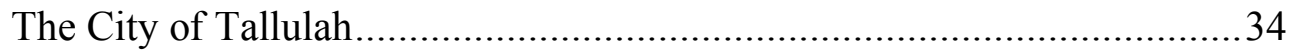

Tallulah Area School District....................................................................

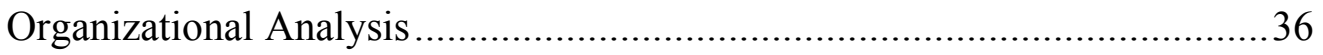

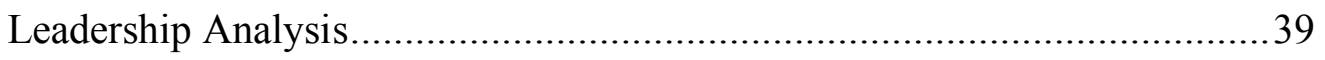

Implications for Research in the Practitioner Setting ....................................4 41

Summary …

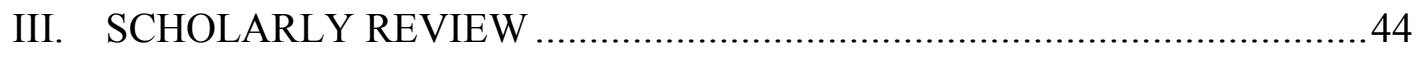

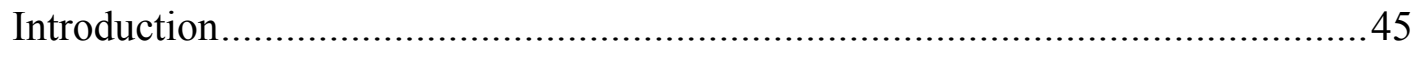

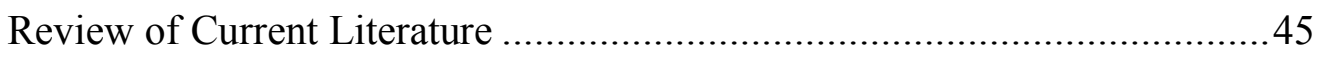

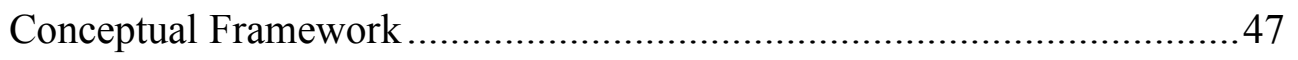

Purpose of Diversity Clubs ……………............................................... 51

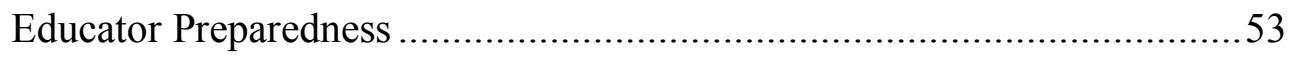

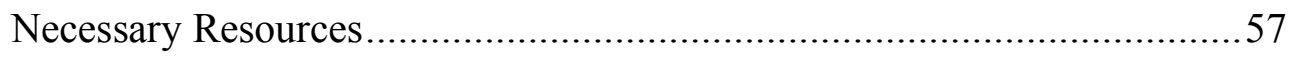




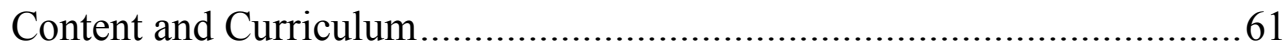

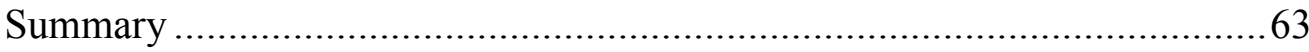

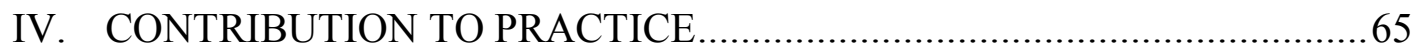

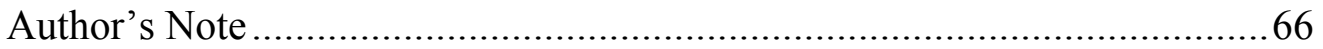

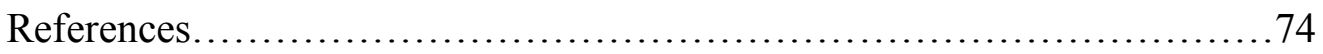

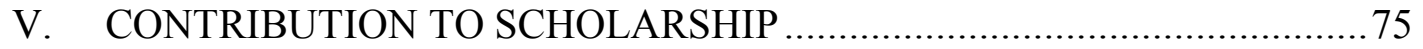

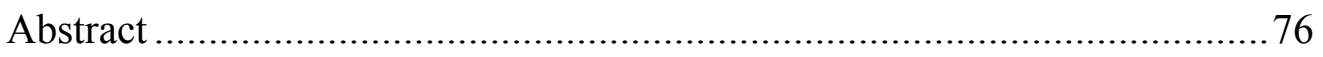

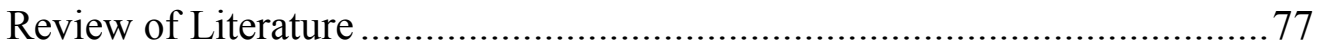

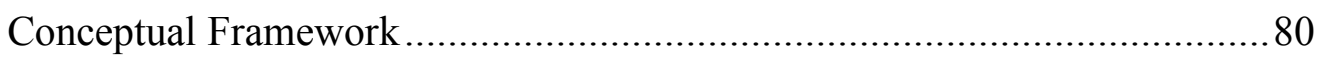

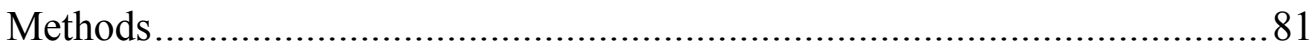

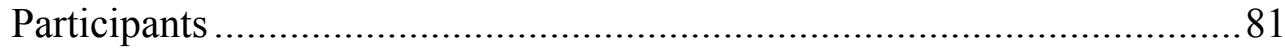

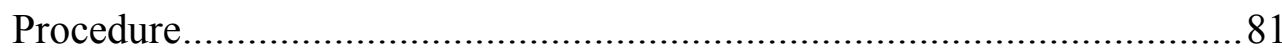

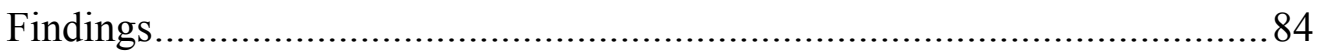

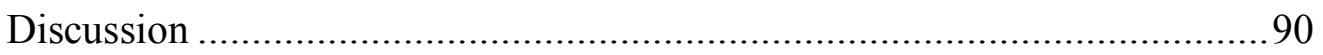

Limitations and Future Research ..............................................................91

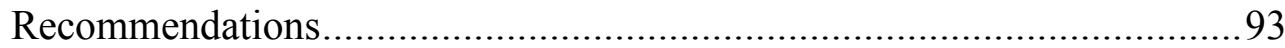

References....................................................... 95

VI. SCHOLARLY PRACTITIONER REFLECTION ......................................99

Influence of the Dissertation on My Practices as an Educational Leader.....100 Influence of Dissertation on Me as a Scholar.............................. 104

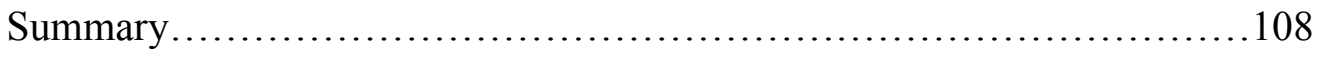

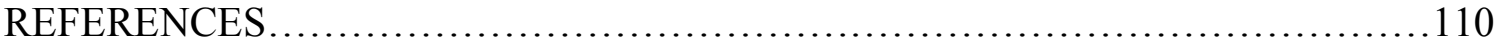

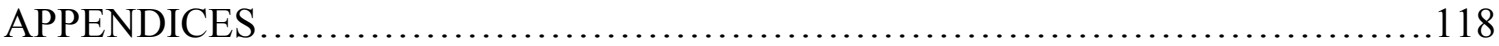




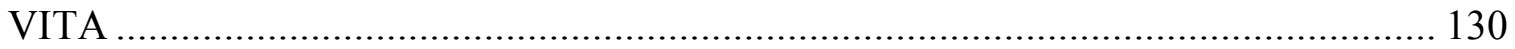


Case Study of Southwestern Wisconsin Conference High School Diversity Clubs: Advisor Qualifications, Club Resources, and Multicultural Curriculum

\author{
Brittany Cox Parry \\ Dr. Jeffrey Cornelius-White, Dissertation Supervisor
}

\begin{abstract}
This mixed-methods case study was conducted to gain principal and diversity club advisor insight into the organization of high school diversity clubs. The focus of this study was specifically on advisor qualifications, club resources, and multicultural curriculum. The data collected was derived from five public high schools in a southwestern Wisconsin conference, and included eleven participants. The study was accomplished through two data collection methods: online surveys and interviews. The surveys were analyzed using quantitative analysis, specifically frequency distributions, and open-ended responses were analyzed with in-vivo coding to determine the best follow-up questions to ask in the interview process. Interview questions were all qualitative in nature and were analyzed with in-vivo methods, allowing for the creation of three key themes and four emerging themes. Interview responses coupled with the survey responses indicated principals and advisors did not place much emphasis advisor qualifications. Instead, the organization of the diversity clubs stemmed from resources and curriculum provided to both the club and the advisor of the club. Findings helped provide insight into examples of curriculum, professional development, resources, and funding, and showed a need for further investigation into the most effective practices of diversity clubs in the goal of promoting inclusion and multicultural education.
\end{abstract}


Keywords: Diversity Club, Advisor Qualifications, Professional Development,

Funding, Multicultural Curriculum 
SECTION ONE:

INTRODUCTION TO DISSERTATION 


\section{Introduction}

Ms. Haas looks around the classroom as the clock ticks to 3:10 p.m.

Anxious about the number of students in attendance, a mere six, she begins to contemplate why she took this role. She introduces herself to the group, although more than half of the students are previous or current students in her English classes, and says, "The purpose of this club will be to learn about diversity in all forms and how to embrace this diversity in a school setting. Our goal is to make all students, regardless of sex, gender, race, ethnicity, ability, etc. feel comfortable attending Green Acres High School.”

She glances at the faces, eager to learn and eager to discuss the hard topics weighing on their minds since entering the high school arena. She thinks so many of these kids are capable of engaging in difficult dialogue but I am not trained to facilitate those conversations. I am definitely not confident in how I will meet the principal's goal of this club, which is to improve an entire school's cultural climate.

She sighs, puts on a smile, and begins the lesson. The lesson is building to a learning opportunity that will promote difficult discourse.

"Today I hope to discuss how we can encourage diverse students to participate in discussion about diversity-perhaps even bring them to a diversity club meeting. As you can see looking around, all the students in attendance are white. Currently, this group is very mono-racial and exhibits little diversity."

Silently and unnoticeably, a student in the fourth row sinks a little in his seat. The student is Puerto Rican and thinks, Great. Again, I am classified as a white student and my cultural experiences will not be shared. 
An article published by Race Bridges for Schools (2007) focused on starting and sustaining diversity clubs at the high school level stated a person must "educate yourself" when beginning a diversity club (p. 2). I believe the narrative above is an accurate, although fictional, example of what a lack of "educating yourself" can resemble. The example also shows the implications in a high school setting where administration has not provided adequate resources for educators serving as an advisor for diversity-related student organizations.

Armstrong, Henson, and Savage (2001) suggested that educators need to make diversity a central theme in schools. As society places greater emphasis on cultural awareness, our schools reflect this societal shift. The primary problem with this shift is the lack of response in educator preparation programs to produce educators confident in multicultural education. Keengwe (2010) stated, “A great majority of preservice educators who wish to teach in diverse racial, ethnic, and socioeconomic settings are unprepared for the cultural diversity they will face in those schools because they have learned little or nothing about it" (p. 198). The problem is intensified when the focus of an educator's work moves to advising a diversity club.

Although an educator's discomfort with leading multicultural clubs or conversations may stem from a lack of multicultural education experiences in their preservice preparation, this study illuminates various other factors currently hindering diversity-related clubs. This research can hopefully in turn be used to guide other facets of multicultural education attempts in the public-school setting. 


\section{Statement of Problem}

The National Center for Education Statistics (2017) stated, "In fall 2014, the percentage of students enrolled in public elementary and secondary schools who were White was less than 50 percent for the first time and represents a decrease from 58 percent in fall 2004" (p. 1). The 2010 census depicted $21 \%$ of children between the ages of 5 and 17 speaking a language at home different from that at school (National Center for Education Statistics, 2010). With an ever-growing diverse student population, school leaders are testing various ways to incorporate multicultural education into the school's curriculum. One approach to multicultural education has been the development of diversity-related clubs. For the purposes of this paper, diversity-related clubs will be referred to as diversity clubs. Diversity clubs range in purposes, goals, and curriculum. A diversity club may have an emphasis on LGBTQ+ matters, such as GayStraight Alliance, or may focus on learning about various cultures around the world, such as an International Cultures Club. Regardless of the title of the club, diversity clubs appear to be growing or maintaining in presence. However, they are heavily underresearched, making it a challenge to establish and maintain an effective extracurricular opportunity for students in this area.

School leaders are encouraging educators to promote cultural competence both in the classroom and in extracurricular learning opportunities because research over the past two decades demonstrates a positive relationship between diversity related curricular activities and civic outcomes (Cole \& Zhou, 2014). However, educators often do not feel capable or prepared to lead such learning opportunities. A study conducted by Assaf, Garza, and Battle (2010) found "many of their teacher educator participants felt unsure 
about their abilities to prepare students to teach 'interculturally' because they did not feel adequately knowledgeable to do so" (Gorski, 2012, p. 220). While there is evidence of the importance of multicultural education in schools, there is little to no research on teacher preparedness in advising student organizations with a focus on diversity.

There is a large amount of data on educators' personal knowledge of multicultural education, but very little research on how this does or does not prepare educators for the leading of student organizations. According to Niska (2013), advisors require professional development that contains both content and skills that "may best support the ability of advisors to apply knowledge to practice" (p. 1). The lack of research on educator preparedness to advise diversity-related student organizations coupled with research displaying educator feelings of unpreparedness proves a necessity for further research on opportunities that would benefit educators. Researchers Gorski, Davis, and Reiter (2012) discussed the limited opportunities, and understanding, many educators have about multicultural matters due to a disproportionate number of white educators. Creating opportunities for educators to experience diversity firsthand could aid in educators feeling confident to lead diversity clubs.

Another significant literature gap discovered when researching diversity clubs is the identification of necessary resources to support the educator advisor, including professional development opportunities, financial compensation for club advisors, and funding for supplies. In a well-funded school district students are granted a variety of learning experiences that are rich in nature and challenge the students (Makina, 2014). It is important to consider how the school district is financially and professionally supporting advisors through resource allocation. 
Lastly, the third literature gap is found in the overall content and curriculum as it relates to incorporating multicultural education in diversity clubs specifically. If school leaders are approving diversity clubs as a way to promote an empowering school culture, it is crucial that curriculum be considered the first step in the transformation (Banks, 1995a). Having a set curriculum to cover during the club's meetings will create a sense of direction for the group and promote student understanding of multicultural education.

Schools are implementing diversity clubs and, due to major literature gaps, are unable to secure answers to the three following significant questions to support and guide their efforts: (a) how are educators effectively prepared to lead a diversity club, (b) what resources successfully support an advisor, and (c) what content and curriculum should be covered in the diversity club?

\section{Purpose of the Study}

There is extremely limited research on advising a diversity club. Therefore, school leaders are unsure of what qualifications and resources are necessary to effectively promote multicultural education and inclusion through such student organizations. The purpose of this study was to organize research and provide guidelines in the following areas: advisor qualifications, resources for advisor (including professional development), and content and curriculum for diversity related student organizations. This foundational research will aid in further research that can delve into each aspect of the diversity club. Until research is conducted on the basic origins of these diversity clubs, it will be difficult to research them any deeper.

With research such as that provided by Assaf, Garza, and Battle (2010), educators are presented with the dilemma that educators do not feel knowledgeable about 
multicultural education and how to discuss diversity. Future school leaders interested in promoting cultural diversity should be interested in improving the experience of students in diversity clubs by providing the right tools for their educator advisor. Further, school leaders should be concerned in how the potential lack of resources and educator qualifications impact students in student organizations focused on diversity.

This study identifies what training or other helpful preparation specific to multicultural education was provided to educators who feel confident in their ability to lead such student organizations, and what content covered in the curriculum leads to difficult dialogue with the intention to make a more culturally competent student. For educators uncomfortable with their multicultural education knowledge, this study highlights what training and professional development opportunities they believe would enhance their advising capabilities.

The impact of educator feeling of preparedness on cultural knowledge of students within a diversity club cannot be overlooked; a very significant relationship is occurring between the educator-advisor and student participants. Students should arguably be gaining cultural knowledge due to the experiences in a diversity club. Research on the topic was unsuccessful in finding a single journal article that linked advisor preparedness to the actual knowledge gain experienced by students. Such research is crucial in identifying the impact a diversity club may or may not have on the student participants, the key stakeholder group in a school setting. 


\section{Research Questions}

The research questions guiding this study are:

1. In regard to preparation of educators to lead diversity clubs, what qualifications do these advisors hold?

2. In what ways, if any, does building administration provide these advisors with resources to aid in the establishment and future endeavors of the student organization?

3. What content and curriculum is used to guide extracurricular instruction and activities?

\section{Conceptual Framework}

A conceptual framework is used to help organize ideas and structure a study. For the purposes of this study, Banks' (2001) multicultural education theory and Bass' (1985) transformational leadership theory served as the conceptual frameworks. The first concept focuses on utilizing resources, content, and curriculum to promote inclusion of students through diversity clubs. Banks' theory also aided in framing questions related to educator leader qualifications. The second concept of transformational leader was relevant to the identification and development of qualified educators who lead diversity clubs with the intent of improving school culture and cultural competency.

\section{Banks' Multicultural Education Theory}

Banks' (2001) multicultural education theory was a natural fit as diversity clubs tend to focus on multicultural education as a key way of eradicating cultural tensions (Leistyna, 2001). Banks (2013) also recognizes the importance of multicultural education so that "their (minority) histories, struggles, contributions, and possibilities can 
be reflected in textbooks and in the school curriculum" (p. 74). With the intent of diversity clubs being to eradicate social tensions between various student populations and to promote inclusion, Banks' theory provides further insight into these goals.

After the Civil Rights Movement and the creation of the ethnic studies movement, educators began to realize that reforming school curriculum to include diverse ethnic and racial groups was necessary in promoting educational equality (Banks, 2013, p.

75). According to Bell (1975), the study of ethnicity and diversity became evident in schools and universities. During the 1980s, there was a shift from international diversity to a focus on national identity as it related to diversity education. In the 1980 s, a list of variables that needed to be reformed was created by educational diversity reformers, including school policy and politics, school culture and hidden curriculum, languages and dialect of the school, instructional materials, etc. (Banks, 2013, p. 75). Upon recognition of the various changes that must occur to promote inclusion of all students, Banks established a new approach to teaching called equity pedagogy. Equity pedagogy is the belief schools must "respect and reflect the rich cultural strengths of students from diverse groups and use teaching strategies consistent with their cultural characteristics" (Banks, 2013, p. 76).

Goodwin (1980) argued that if multicultural education was to be better understood, and implemented in various educational settings, there must be clear dimensions that were described in a way that could be easily implemented. Banks was one of the numerous researchers who created a clear framework and thus the Banks' multicultural education framework originated. Banks (2001) presents the five dimensions of multicultural education as a conceptual framework: content integration, 
knowledge construction, equity pedagogy, prejudice reduction, and empowering school culture and social structure.

Banks' (2001) framework has been used in multicultural education research in K12 settings to advise groups on how to make education more inclusive (Cole \& Zhou, 2013). This study will focus on two tenets of this conceptual framework: knowledge construction, and empowering school culture and social structure.

Cole and Zhou (2013) explained knowledge construction as "instructors help students understand, investigate, and determine how the implicit cultural assumptions and biases influence the ways knowledge is constructed" (p. 111). Research question three will provide information about how advisors help students understand, investigate, and determine their own cultural assumptions. Empowering school culture and social structure refers "to how educators, students, parents, and the community create a transformative ethos that enables students from diverse groups to experience equality" (Cole and Zhou, 2013, p. 111). All three research questions will provide information regarding how diversity clubs contribute to a school culture that enables students from diverse groups to experience equality. Both of these aspects from Banks' (2001) theory relate to the advisor's ability to teach and cultivate student cultural competency, and explore the relationship of the diversity club to the school's overall levels of cultural competence. This theory's focus on knowledge construction and empowering school culture provided a lens to view research on curriculum and resourcing as they pertain to diversity clubs. 


\section{Bass' Transformational Leadership Theory}

Transformational leadership was a vital part of the framing of questions and research of this study as the major purpose of this study is to provide data about the current state of educators functioning as leaders of diversity clubs (Bass, 1985). The first research question of this study focused on educator qualifications to lead students in diversity clubs, specifically as it relates to difficult dialogue. Research question three also related to educator knowledge in the creation of curriculum for the diversity club. Transformational leadership, as succinctly defined by Northouse (2016), is "a process that changes and transforms people" (p. 161). Bass (1985) believes transformational leadership is also a process; a process that increases awareness of task importance, focus on team or organizational goals, and activate higher-order needs. Educators leading diversity clubs should be providing opportunities for students to transform their beliefs and behaviors.

Transformational leaders exhibit several key behaviors: sets strong role model, shows competence, articulates goals, communicates high expectations, expresses confidence, and arouses motives (Bass, 1985; Northouse, 2016). The transformational leader behaviors that relate to this study, specifically research questions number one and three, are: articulate goals and appear competent to followers. Diversity club educator advisors must appear competent to followers by having or acquiring knowledge about multicultural education topics. Bennis and Nanus (1985) discovered that people identified as transformational leaders all had a clear vision of the future state of their organizations. Transformational leaders are capable of initiating change when transformation is crucial to the overall success of an organization (Bass, 1985). A clear 
vision for diversity club can be established by the articulation of the club's goals. Jason (2000) stated, “The nature of teaching, and the value of colleagues' expertise, influence the level of individual and collective motivation to learn" (p. 1). When considering expertise and knowledge of diversity club advisors, this study aims to provide information about the qualifications educators possess that may influence student learning. The purpose of this study is not to identify who is and who is not a transformational leader, instead it will focus on the knowledge and expertise of such leaders, and their ability to create curriculum that maintains a clear goal.

Transformational leadership and Banks' multicultural education theory will also couple together well as they aspire for shared goals within an organization. Marshall (1995) stated, "A major tenet undergirding the study of multicultural education is that educators can serve as transformative agents within schools. This involves making problematic those aspects of schooling that serve to perpetuate the inequitable treatment and disempowerment of many groups" (p. 1). Banks' multicultural education theory and transformational leadership as conceptual frameworks aided in the structuring of this study. Each theory reflects the other in its' own ideas and concepts.

\section{Design of the Study}

\section{Setting}

The setting of this study was rural Wisconsin in the Southwestern Wisconsin Conference. Due to the small sample size, the name of the conference utilized in the study remained anonymous through the use of the pseudonym "Southwestern Wisconsin Conference." This conference is comprised of six public high schools and one private high school in the southwest part of Wisconsin. The private school within the conference 
does not have a diversity club and was therefore omitted from the study. The setting was selected due to the proximity of the schools to each other and the similar population sizes within each school. Although the diversity within each school district varies, each high school within the study contains one ethnicity with a population significantly higher than the state average, thus creating a commonality between the schools in the Southwestern Wisconsin Conference. Four of the six high schools exhibit a significantly higher Asian population compared to the state average and surrounding districts. The other two high schools show an increase in an individual ethnicity as well: The School District of Stockton has an $8.3 \%$ Hispanic population compared to the state average of $6 \%$, and the School District of Tallulah has a 3.5\% American Indian population compared to the state average of $1 \%$.

\section{Participants}

The participants for this study were the educator advisors for each of the diversity clubs and a member of the administrative team at each individual high school. This sample was selected by first identifying a general area accessible to conduct the study. Once a general area was decided upon, it became apparent the sizes of the school districts varied greatly. School districts are placed in sports conferences based on the size of the school, and the proximity of other schools within the state. By selecting a sports conference, Southwestern Wisconsin Conference, the parameters of the sample were defined. The Southwestern Wisconsin Conference includes six public schools, one private, and one affiliate, representing a total student population of approximately 55006500 high school students. Due to the specificity of the sample, random sampling could not be utilized. This allowed for direct sampling (Creswell, 2014, p. 158). Direct 
sampling was necessary due to the limited number of potential participants in the study. Interactive phenomenological researchers also indicate that purposive, direct sampling of a fairly homogeneous sample is more significant (Smith \& Osborn, 2008). Finding school districts with samples containing the same exact socioeconomic status and ethnic background was impossible, even within neighboring communities. Purposively selecting a direct sample most similar in size, socioeconomic status, and ethnic background aides in creating more significant data and increased transferability.

According to the Wisconsin Department of Public Instruction's nondiscrimination guidelines for athletics and activities, the following factors are considered in determining whether a program or activity is approved or sponsored by a public school board: "the provision of direct or indirect financial support; the provision of tangible resources; intangible benefits such as lending recognition or approval to a program or activity; the selectivity of the school board in providing privileges and resources to various programs and activities; and whether the relationship is occasional and temporary or permanent and long term" (Wisconsin, 2013, p. 4). All diversity clubs appearing within the study are considered school sanctioned clubs as outlined by the DPI.

The Wisconsin Department of Public Instruction implemented Culturally Responsive Education to encourage the education of all students. According to the DPI (2017), "Culturally responsive practices account for and adapt to the broad diversity of race, language, and culture in Wisconsin schools and prepare all students for a multicultural world." (p.1). This definition guided the classification of clubs within the study as diversity clubs. Clubs with a focus on preparing students for a multicultural world, specifically in the areas of race, language, and culture, were included. The title of 
clubs, mission statements, and club activities were used to determine if the club focused on multiple cultures. An example of this would be the Gay-Straight Alliance Network due to their mission statement: "To create a platform to fight for racial, gender, LGBTQ, and economic justice" (GSA, 2009). Although the club centers around LGBTQ+ matters, themes of racial inequality and economic justice are also evident. Clubs focusing on one sole culture were excluded from the study. An example of this would be the Fellowship of Christian Athletes because there is no mention of diverse groups within their mission and vision statement.

Each high school was contacted to determine what diversity clubs are offered at each respective high school. The private school does not have a diversity-related club and therefore is omitted from further research in this study. The affiliate school is considered a member of the Coulee Conference and will also not be researched in regard to the study. Upon discovering that all six high schools had a minimum of one diversity club, The Southwestern Wisconsin Conference was formally identified as the setting and the student organization sponsors as the participants. The diversity clubs in each high school are as follows: School A: Amnesty International Club, Culture Club, Feminist Club, Gay-Straight Alliance, and Centerville Students United; School B: Gay-Straight Alliance and Understanding Cultural Differences; School C: Diversity Club and GayStraight Alliance; School D: International Cultures Club; School E: Spectrum GayStraight Alliance; and School F: International Club and Ho Chunk Youth Program. There are 13 identified clubs. A central focus of each club is the inclusion of diverse student populations. 
Communication was established with the administrative assistants of each high school, and further contact was made with each student organization advisor and a building level administrator. In several instances, guidance counselors within the high school served as a point of contact as they are directly linked to the creation of the diversity club. Each high school had an updated website with staff emails. Each administrative assistant was called to learn the name of the student organization advisors and begin initial conversations via email. Face-to-face meetings were arranged to provide information and the purpose of the study.

\section{Data Collection}

For data collection, three different strategies were employed. The first was a survey that includes both open ended qualitative questions, and Likert scale quantitative questions. Due to the combination of qualitative and quantitative objects, this study was a mixed-methods study. The use of both quantitative and qualitative data allowed for one set of data to build upon the other. This approach also provided various research tactics that allow for triangulation of data. The survey research is quantitative in nature due to the numeric description of the data (Creswell, 2014). According to Creswell (2014), qualitative research is an approach "for exploring and understanding the meaning individuals and groups ascribe to a social or human problem" (p. 4). The consideration of cultural awareness in public high schools is both a social and human problem; therefore, a qualitative, interactive phenomenological study provided more individualized responses. The study focused on a specific qualitative design, phenomenological study, due to its "description culminating in the essence of the experiences of several individuals who have all experienced the phenomenon" (Creswell, 2014, p. 14). Data 
gained through this study provided insight into the experiences of diversity club advisors and building principals, both shared and differing.

Creswell (2014) advised researchers to ask one or two central research questions that explore the central phenomenon of the study. Participants were asked to participate in a survey that included ten questions, with two central questions and eight subquestions. Four of the questions provided qualitative data through open-ended questions, and six of the questions provided quantitative data through Likert scale rankings (see Appendix A and Appendix B). The survey was distributed by email for the convenience of the participants (Fink, 2017). Based on past experiences, the survey was distributed with enough time to allow the participants two full weeks to complete the survey. Also reflecting on past research experiences, allotting more than a two-week time frame for the completion of the survey would have caused participants to linger and potentially forget about the survey. Reminder emails were sent after about the one-week mark has passed to aid in obtaining surveys. A $100 \%$ response rate was expected due to the small size of the participant pool. A small sample will "sacrifice breadth for depth," thus meeting the overall objective of interactive phenomenological studies: to provide an in-depth account of one's personal lived experience (Smith \& Osborn, 2008, p. 56). Participation from all six public schools in the entire conference would have been of great value to allow the research of schools similar in size and demographics to analyze repeating themes evident in the various school districts.

Second, at least one administrator per school building was asked via phone call to participate in an interview to gather more qualitative data (see Appendix E). Also, the advisor for each diversity club within an individual high school was asked to participate 
in the study. This phenomenological approach allowed the researcher to focus on the "experience of the participants and the meaning they make of that experience" (Seidman, 2013, p. 16). Interviews included five follow-up questions based on the survey responses from the same study participants (see Appendix C and Appendix D). The stories told by advisors through the phenomenological interview process were crucial to answering the study's research questions as they provided insight into the lived experience of advising diversity clubs. Utilizing a phenomenological approach strengthened these insights because "it involves a detailed examination of the participant's lifeworld; it attempts to explore personal experience and is concerned with an individual's personal perception or account of an object or event" (Smith \& Osborn, 2008, p. 53). Follow up commentary was solicited to supplement topics not covered in other lines of questioning.

Questions appearing in the survey and interview process related to this study's frameworks: Banks (2001) multicultural education framework and Bass (1985) transformational leadership. The guiding research questions related to student knowledge and empowering school culture will be evaluating how diversity clubs are effectively or ineffectively creating multicultural education experiences for students. The three research questions aimed to discover what qualifications, resources, and content and curriculum must be present for multicultural education experiences and activities to be effective in promoting inclusion through difficult discourse, thus leading to student knowledge and an empowered school culture. Questions framed by transformational leadership traits related to educator knowledge and how it impacts student learning through the development of curriculum. Given the realization that there is a substantial literature gap in this field of research, the answers to these foundational questions were 
necessary to set the stage for further research about student organizations focused on diversity.

\section{Data Analysis}

Data analysis methods included coding of qualitative responses gathered through surveys and interviews (Creswell, 2016). In-vivo coding is the process of maintaining the integrity of a study participant's actual words creating codes with a word or phrase spoken directly by the participant (Creswell, 2016). In-vivo coding was utilized because it "enables us to access the participant's perceptions directly, without obstructing them by the theories we develop" (Creswell, 2016, p. 23). The coding process began the reading of each text, coding of each text, and listing of all codes. Next, codes were grouped and redundant codes were eliminated. Finally, a conceptual map was created and a narrative story was developed for the conclusion (Creswell, 2016).

Quantitative data analysis also occurred using data gathered from the Likert scale questions. This was analyzed using descriptive statistics such as graphics analysis and frequency distributions (Fink, 2013; Field, 2013). There was no prior data in this area of study so all data was analyzed by the researcher as the sole scholar in this arena.

To ensure validity and reliability of the data, data was triangulated through the disbursement of multiple qualitative research techniques: surveys and interviews. The convergence of multiple sources, study of participants, and recognition of emerging themes established reliability and validity (Creswell, 2014, p. 201). By triangulating data, personal bias was addressed and did not appear in results because the integrity of the participants' responses will be intact. By selecting school districts similar in size and demographics, commonalities in the themes emerged. Each high school setting serves a 
unique student population, so generalizability was hard to accomplish. However, suggestions that emerged in regard to resources that best aid student organization advisors may be transferable to other studies centered on student organization advisement. Research transferability is accomplished "when the findings fit into other contexts and are meaningful to individuals not involved in the research study" (Ryan, Coughlan, \& Cronin, 2007, p. 743). Transferability enables other diversity club advisors to relate to the findings of the study, thus modifying their own leadership to best serve students.

\section{Limitations, Assumptions, and Design Controls}

One of the limitations of this study relates to data collection. There are no specific measurement tools previously created that related to this study. Therefore, there was no matrix or previous data with which to compare my findings. The lack of a matrix and previous data led to a missed opportunity to establish additional validity and reliability of my data.

Another limitation was the varying number of diversity related clubs within each school district. When beginning the initial research for this study, I was living in Missouri. I had a specific school conference in mind for the participant section of the study. After moving to Wisconsin, I realized the distance between where I currently reside and the selected conference would create too many traveling barriers to overcome whilst teaching full-time. The school conference selected for this study has a relatively high number of diversity related clubs. However, the private school within the conference does not have a diversity related club, which automatically decreased the number of research participants. 
Diversity within each school district is evident in at least one ethnic population being higher than the state average. High schools within the study exceed the state average in the following populations: Centerville High School 8.2\% Asian population, Lindberg High School 12.34\% Asian population, Stockton High School 8.3\% Hispanic population, Owensville High School 7.7\% Asian population, and Tallulah High School 3.5\% American Indian population. Despite having an increase in one demographic within each school district, there is a limited amount of diversity when comparing each individual school district to the state average. However, despite this lack of diversity multicultural education is still necessary. Gordon (2004) stated, "A goal of education is to help students to become more aware and to challenge political, social, and educational systems that perpetuate institutional racism and discrimination" (p. 28). Multicultural education is not exclusively taught in schools displaying diversity; multicultural education seeks to teach all students about cultural awareness.

In addition to holding the key researcher position in this study, I am also an educator. I work in a school district that does not have a diversity related club. However, I previously worked for a school district where I was an advisor for a diversity related club for two years. I started this club because I felt my students were not engaged in difficult discussions about diversity and inclusion during the school day. I feel very passionately about the value of both extracurricular opportunities for high school students and the need to include multicultural education elements into every potential facet of student learning. My interest in the extracurricular activities that provide students with opportunities to discuss difficult dialogue is what led me to the idea of this study. My personal and professional experiences both influence my assumptions. I consider these 
factors when considering the potential biases, I brought to the study. In order to address these personal biases, I was transparent about my position as a researcher. The transparency of researcher bias, triangulation of data, and in-vivo coding kept my personal bias in check while analyzing data in a fair and ethnic manner, keeping the integrity of participants' responses.

In order to complete the research study, a mixed methods approach was selected, and a quasi-experimental design was utilized. As stated by Creswell (2014), a quasiexperiment is one where individuals are not randomly assigned; the selection of participants was deliberate (p. 168). I limited my data to what is collected from the survey and interview processes. All data collection took place within a few month timeframe to avoid a turnover of diversity club advisors and changing perspectives from one data collection method to the next.

\section{Definition of Key Terms}

One of the terms used continuously throughout this study was "diversity related club." In the case of this study, the term diversity related club was used in reference to any high school club formed with the purpose of promoting the inclusion of diverse students. I looked for clubs that specifically state multicultural education, student inclusion, or increased cultural awareness as a goal of the club.

The term "club advisor" was also used in this study interchangeably with "educator advisor." Oftentimes the person leading the diversity club is an employee within the school district, specifically an educator or counselor. The club advisor is responsible for setting meetings, organizing student activities, and teaching curriculum 
within the diversity club. To clarify the role, the term advisor is used in most references of the position.

\section{Significance of the Study}

The significance of this study is that schools are promoting cultural awareness so students are prepared to engage in a diverse world after high school in ways that are both ethical and equitable. With the diversity evident in today's classrooms, it is important students are taught about the vast diversity America represents in race, ethnicity, sexual orientation, socioeconomic status, etc. These lessons are crucial in encouraging students of both diverse and non-diverse backgrounds to be cognizant of their own white bias (Banks, 1995b). Research shows that this awareness helps students create more democratic racial attitudes and views (Banks, 1995b).

Although the value of cultural awareness in schools is well-researched, researchers have yet to question the educator perception of preparedness when leading lessons about diversity or advising student organizations centered on diversity and cultural awareness. Lessons are desired about diversity in public education yet it has not been really considered yet how those conversations are being led and by whom- a qualified advisor or an educator with limited knowledge about multicultural education, and limited resources.

Research on educator knowledge of diversity and multicultural education is abundant but the research on diversity club advisors' knowledge, qualifications, resources, and choice of curriculum are almost nonexistent. This study adds data to the limited literature on how educators are effectively or ineffectively prepared to advise student organizations created with the intention to increase cultural competency of 
students within a public high school setting, and provides specific suggestions on how to best prepare educators for an advising role.

For school leaders, it is critical to know how to best support educators in this role of an advisor. However, research is unavailable to determine what curriculum should be taught, what professional development should be offered to the educators, what resources should be provided for the educators, and even how best to compensate the educators if necessary. This study provides guidelines for school leaders to use when establishing diversity clubs in the hopes students are gaining an impactful multicultural education experience. This research can also be extended to multicultural education occurring within the classroom. Yet again, the literature on what curriculum should be utilized when teaching multicultural issues is very limited. As diversity in schools continues to increase, this study and the research behind it will progressively become more relevant and necessary.

\section{Summary}

Research showing educator feelings of unpreparedness to lead discourse about diversity and multiculturalism combined with a lack of research on how to help these educators through resource allocation and curriculum development contribute to the significance of this topic. With variations of diversity clubs appearing in schools across the United States, it is crucial there is research to support the advisor's role by outlining best practices, qualifications, resources, and curriculum. The sole purpose of this research was to aid in establishing guidelines for diversity clubs so students are receiving the best possible experience in diversity clubs. 
The first framework selected, Banks' (2001) multicultural education, was a natural selection as it pertains directly to these student organizations' goals in teaching multicultural educational topics within their extracurricular activities. Banks' theory encompasses student knowledge and an empowering school culture, both of which relate to the research questions aiming to discover what students are learning and how this is impacting the overall school culture.

The second framework selected, transformational leadership, also provided direction for the study by establishing the diversity club advisor as a leader within the school building who is accountable for student learning. Transformational leadership identifies specific qualities a leader must exhibit to encourage students and achieve specific goals. In the case of this study, the goals relate to the multicultural education experiences of high school students.

Schools in the Southwestern Wisconsin Conference may provide an accurate portrayal of the vast number of schools who have implemented some form of an extracurricular student organization focused on diversity and cultural awareness. With little to no research on what makes an effective advisor for these student organizations, this study is instrumental to administrators hoping to create such an organization or improve a current diversity club. 


\section{SECTION TWO:}

PRACTITIONER SETTING FOR THE STUDY 


\section{Introduction}

This section will discuss the practitioner setting of the study, beginning with the organization. Also discussed is each school district within the study and relevant school leadership. The history begins with a broad overview of the increasing diverse populations within the United States and will then focus more specifically on how racial and economic diversity is present in the state of Wisconsin. Racial and economic diversity will be included in this study because it is the only data related to diverse populations that is consistently measured by both the U.S. Census and by the Wisconsin Department of Public Instruction. The intention of providing this information is to provide context for the increase in diversity related clubs within public high school schools across the nation. An organizational and leadership analysis will provide context for the research in the practitioner setting.

\section{History of Organization}

While this study focuses specifically on the school districts within the Southwestern Wisconsin Conference, it is important to first look at the increasing diverse populations in the United States as a whole. This allows for better understanding of the demographics reflected in each school district within the study and for school district responses to diversity in the formation of diversity related clubs.

\section{The United States of America}

The 2016 United States Census estimated the total United States population to be $323,127,513$ with a $4.7 \%$ increase in population since April 2010. The Black or African American population was $13.3 \%$, the Hispanic or Latino population $7.8 \%$, the American Indian and Alaska Native population $1.3 \%$, the Asian population 5.7\%, the Native 
Hawaiian or other Pacific Islander $0.2 \%$, and two or more races $2.6 \%$. The percentage of persons living in poverty was $12.7 \%$ (U.S. Census, 2016). Approximately $21.0 \%$ of United States homes spoke a language other than English at home (U.S. Census, 2016). It is estimated there are nine million lesbian, gay, bisexual, and transgender Americans (Gates, 2011). Of these nine million people, three percent live in Wisconsin (Gates, 2011). With Wisconsin's total population of approximately 5.779 million people, approximately $4.67 \%$ of the state's population identifies as part of the LGBTQ+ community. Gates (2011) has tried to gather more timely data but finds it difficult because questions regarding sexual orientation do not appear on all local, state, or national population-based surveys. The same is true of individual high schools as sexual orientation data is not gathered consistently by individual states or school districts. Regardless, these national statistics are indicative of the diverse populations that will be present in our public high schools.

Public elementary and secondary school enrollment increased from 49.3 million in 2008 to 50.0 million in 2013 (NCES, 2015, p. 71). However, public secondary enrollment decreased by $1 \%$ (NCES, 2015, p. 71). Hence, there are younger children in the system. According to the National Center for Education Statistics (NCES) (2015), "Between 2008 and 2013, the enrollment of Hispanic students increased 18\% and the enrollment of Asian/Pacific Islander students increased 6\%” (p. 71). With steadily rising minority populations enrolling in public schools, the opposite is occurring with the majority. The NCES (2015) stated, "By contrast, the enrollment of White students decreased 7\%" (p. 71). 


\section{The State of Wisconsin}

The state of Wisconsin is experiencing slower increase in population compared to the nation as a whole. Between 2000 and 2010, Wisconsin had an increase in population of $6 \%$ compared to the nation's $9.7 \%$ increase (Curtis, 2010). With this increase in population, Wisconsin is nevertheless becoming increasingly more racially and ethnically diverse. According to the 2010 Census, Wisconsin's population is about $83 \%$ White, $6 \%$ Black, 6\% Hispanic, 2\% Asian, and 1\% American Indian (Curtis, 2010). According to Curtis (2010), Wisconsin is more diverse now than in past decades. As of 2010, 26.5\% of youth in Wisconsin are people of color. This is significantly higher than the senior citizens of color, and explains the overall increase in racially and ethnically diverse persons in Wisconsin. Another representation of this growth is in the Hispanic youth population that grew by a full $81 \%$ between 2000 and 2010 (Curtis, 2010). The limited data published from the 2016 U.S. Census shows continued growth in diverse population numbers.

The significance of the increasing population of non-White Wisconsin citizens is this number is also reflected in the populations attending Wisconsin public schools. According to the Wisconsin Department of Public Instruction (2016), 1.2\% of students enrolled in public schools are American Indian or Alaska Native, 3.8\% are Asian, 9.5\% are Black or African American, 11.3\% are Hispanic/Latino, and $71.2 \%$ are White. Comparing these numbers to the state's total population statistics, there is a clear increase in diversity amongst the youth of Wisconsin. 


\section{The City of Lafayette}

Lafayette is a city in Wisconsin that serves as the county seat of Lafayette County. It lies alongside the Mississippi River and has an estimated population of 52,109 (U.S. Census, 2010). In 2010, 0.56\% was American Indian and Alaska native, $4.85 \%$ of the population was Asian, 2.25\% of the population was Black or African American alone, $0.02 \%$ was Native Hawaiian or other Pacific native, $1.97 \%$ was Hispanic or Latino, $89.77 \%$ was White, and $2.15 \%$ of the population was two or more races (U.S. Census, 2010). Although the population of those identifying as Black or African American is lower than the state average, the Asian population is significantly higher.

\section{School District of Lafayette}

As with the state of Wisconsin, the Lafayette census discovered that student age populations represented a greater variety of diversity compared to senior citizen populations. About 10\% of students in Lafayette identified as Asian in 2016, while more than $5 \%$ identified as Black and almost $4 \%$ as Hispanic. Also, according to a local newspaper, almost $9 \%$ identified with two or more races. In perhaps a more telling statistic, since 2005, the School District of Lafayette has seen more than a $41 \%$ increase in nonwhite students.

According to a local journalism article regarding socioeconomic status, there has been a $21.41 \%$ increase in students considered low income and "twelve years ago, 38\% of students were eligible for the lunch program in Lafayette, compared with nearly half of the students in the district in 2016." The increase in both racial diversity and socioeconomic status allude to the ever-growing diverse populations of students within the School District of Lafayette. In an attempt to help meet the needs of the growing 
diverse student populations, the district has created various programs and events. The district has also created several positions within the school to act as cultural liaisons to work with African American, Southeast Asian, and other student groups.

In this study, the two public high schools within the School District of Lafayette will be studied: Centerville High School and Lindberg High School. Centerville High School has 85 full-time employees and 14 full-time teacher assistants. The school is grades 9-12 and has 1042 students (Centerville, 2016). Of the 1042 students, $0.8 \%$ are American Indian or Alaska Native, 8.5\% are Asian or Pacific Islander, 3.9\% are Black, $3.2 \%$ are Hispanic, $78.4 \%$ are White, and $5.1 \%$ are from two or more races (Centerville, 2016). In addition to over $20 \%$ of the student population belonging to a minority race, there is also a significant portion of the population who is recorded as economically disadvantaged: 37\% (Centerville, 2016). Several of Centerville High School's goals relate to inclusion and diversity. Centerville (2016) stated, "CHS will continue our Equity journey by focusing on a shift in school culture with an emphasis on learning and school-wide academics" and "Students will strive for mutual understanding as contributing citizens in a diverse world" (p. 1).

Lindberg High School has 78 full-time employees and 15 full-time teacher assistants. The school is grades 9-12 and has 778 students (Lindberg, 2016). Of the 778 students, $0.64 \%$ are American Indian or Alaska Native, $12.34 \%$ are Asian or Pacific Islander, 5.53\% are Black, 3.73\% are Hispanic, $71.59 \%$ are White, and $6.17 \%$ are two or more races (Lindberg, 2016). Like Centerville High School, Lindberg High School also has a significant number of students who are classified as economically disadvantaged: 48.59\%, almost half of Lindberg's students (Lindberg, 2016). Lindberg High School has 
created several school beliefs related to diversity and inclusion. The first is "we believe intellectual and cultural diversity are valued" (Lindberg, 2016). Like Centerville, Lindberg (2016) has written the following as a school goal: "Students that strive for mutual understanding as contributing citizens in a diverse world" (p. 1).

\section{The Village of Highlandville}

Highlandville is located in northern Lafayette County and is one of Wisconsin's fastest growing communities. In the past thirty years, the population has grown from 2,400 residents to nearly 10,000 residents (Highlandville, 2017). The total population of

Highlandville Village is 9,628 (U.S. Census, 2016). In 2010, 0.19\% of the population was American Indian or Alaska native, $7.01 \%$ of the population was Asian, $0.64 \%$ of the population was Black or African American alone, $0.04 \%$ was Native Hawaiian or other Pacific native, $1.07 \%$ was Hispanic or Latino, $90.39 \%$ was White, and $1.48 \%$ of the population was two or more races (U.S. Census, 2010). Highlandville experiences the same increased numbers in Asian populations as Lafayette.

\section{School District of Highlandville}

Highlandville High School is grades 9-12 and has 1,172 students (DPI, 2016). Of the 1,172 students, $0.5 \%$ are American Indian or Alaska Native, $8.2 \%$ are Asian or Pacific Islander, $1.2 \%$ are Black, $0.8 \%$ are Hispanic, $87.5 \%$ are White, and $1.8 \%$ are two or more races (DPI, 2016). Racial minorities are relatively low, however $27.4 \%$ of Highlandville High School's student population is considered economically disadvantaged (Wisconsin b, 2016). According to Highlandville High School's 2017 Annual Report (2017), one of school's core values is to honor diversity. 


\section{The City of Stockton}

Stockton is the county seat of Monroe County and is located approximately 30 miles from Lafayette. The total population of Stockton is 9,696 (U.S. Census, 2016). In $2010,0.64 \%$ of the population was American Indian or Alaska native, $0.46 \%$ was Asian, $1.51 \%$ of the population was Black or African American alone, $0.08 \%$ was Native Hawaiian or other Pacific native, 6.75\% was Hispanic or Latino, 92.22\% was White, and $1.48 \%$ of the population was two or more races (U.S. Census, 2010).

\section{School District of Stockton}

Stockton, being in close proximity to Lafayette, is also experiencing some increase in diverse student populations. Almost 1 in 6 Stockton School District students are Hispanic or Black. While still modest compared to urban areas of the USA, this is substantially higher than the 1 in 20 students from the 2015 school year, according to a local newspaper. As described in a local newspaper the increase in diverse student populations has caused a decline in the historically White majority; from 2005 to 2017, there has been a $191.97 \%$ increase in non-White students. Stockton High School serves 745 students in grades 9-12 (Wisconsin b, 2016). The Stockton community experiences a high Hispanic population compared to the state average. The student population consists of: $0.5 \%$ American Indian or Alaska Native, 1.2\% Asian, 1.6\% Black or African American, 8.3\% Hispanic, 0.5\% Native Hawaiian or other Pacific Islander, 86.4\% White, and $1.3 \%$ two or more races (Wisconsin b, 2016). Stockton School District witnesses an increased need for free-and-reduced lunch due to $40.5 \%$ of its high school population qualifying as economically disadvantaged (Wisconsin b, 2016). The school goal, vision 
statement, and strategic plans do not specifically mention multicultural education or inclusion of diverse populations as tenants of the school's operations.

\section{The City of Owensville}

Owensville lies directly beside Lafayette and is well-known for being part of the "driftless area," which consists of bluffs formed during the Ice Age. In 2010, the total population of Owensville was 17,736 people (U.S. Census, 2010). In 2010, 0.33\% of the population was American Indian or Alaska native, 5.68\% was Asian, $1.13 \%$ of the population was Black or African American alone, 0.01\% was Native Hawaiian or other Pacific native, $1.56 \%$ was Hispanic or Latino, $90.69 \%$ was White, and $1.71 \%$ of the population was two or more races (U.S. Census, 2010).

\section{School District of Owensville}

Owensville High School serves 894 students in grades 9-12 (DPI, 2016). Owensville has a significantly higher Asian population than either the state average or surrounding communities. The student population consists of: $0.6 \%$ American Indian or Alaska Native, 7.7\% Asian, 2.3\% Black or African American, 2.5\% Hispanic, $0.1 \%$ Native Hawaiian or other Pacific Islander, $84.6 \%$ White, and 2.2\% two or more races (DPI, 2016). Owensville has a lower portion of students who are considered economically disadvantaged with $25.9 \%$ of its student population falling into this category (DPI, 2016).

\section{The City of Tallulah}

Tallulah is called the "Gateway to Cranberry Country" and is believed to have increasing diversity due to the intersection of two major interstates. The total population

of Tallulah is 9.405 (U.S. Census, 2016). In 2010, 1.74\% of the population was American 
Indian or Alaska native, $1.21 \%$ was Asian, $2.62 \%$ of the population was Black or African American alone, $0.27 \%$ was Native Hawaiian or other Pacific native, $4.03 \%$ was Hispanic or Latino, $90.86 \%$ was White, and $2.18 \%$ of the population was two or more races (U.S. Census, 2010).

\section{Tallulah Area School District}

Tallulah High School serves 912 students in grades 9-12 (DPI, 2016). Tallulah High School has a significantly higher American Indian population than surrounding school districts due the school's proximity to the Ho Chunk Nation. The student population consists of: 3.5\% American Indian or Alaska Native, 0.7\% Asian, 1.8\% Black or African American, 3.4\% Hispanic, 0.0\% Native Hawaiian or other Pacific Islander, $89.3 \%$ White, and $1.4 \%$ two or more races (DPI, 2016). Over one-third of the student population is considered economically disadvantaged with $37.6 \%$ (DPI, 2016).

Table 1 provides an overview of the ethnicity and free/reduced lunch rates of the high schools included in the proposed study. 
Table 1

Comparison of Ethnicity and Free/Reduced Lunch Rate of High Schools Within the Study

\begin{tabular}{|c|c|c|c|c|c|c|c|}
\hline \multirow{2}{*}{$\begin{array}{l}\text { High Schools } \\
\text { Within } \\
\text { Southwestern } \\
\text { Wisconsin } \\
\text { Conference }\end{array}$} & \multicolumn{6}{|c|}{ Percentage of Students of Various Ethnicities } & \multirow[b]{2}{*}{$\begin{array}{l}\text { Percentage of } \\
\text { High School } \\
\text { Population } \\
\text { Eligible for } \\
\text { Free/Reduced } \\
\text { Lunch }\end{array}$} \\
\hline & $\begin{array}{c}\text { American } \\
\text { Indian or } \\
\text { Alaska } \\
\text { Native }\end{array}$ & $\begin{array}{l}\text { Asian or } \\
\text { Pacific } \\
\text { Islander } \\
\text { or Native } \\
\text { Hawaiian }\end{array}$ & $\begin{array}{l}\text { Black or } \\
\text { African } \\
\text { American }\end{array}$ & Hispanic & White & $\begin{array}{l}\text { Two } \\
\text { or } \\
\text { more } \\
\text { races }\end{array}$ & \\
\hline $\begin{array}{l}\text { Centerville } \\
\text { High School }\end{array}$ & $0.8 \%$ & $8.5 \%$ & $3.9 \%$ & $3.2 \%$ & $78.4 \%$ & $5.1 \%$ & $37 \%$ \\
\hline $\begin{array}{l}\text { Lindberg } \\
\text { High School }\end{array}$ & $0.64 \%$ & $12.34 \%$ & $5.53 \%$ & $3.73 \%$ & $71.59 \%$ & $6.17 \%$ & $48.59 \%$ \\
\hline $\begin{array}{l}\text { Highlandville } \\
\text { High School }\end{array}$ & $0.5 \%$ & $8.2 \%$ & $1.2 \%$ & $0.8 \%$ & $87.5 \%$ & $1.8 \%$ & $27.4 \%$ \\
\hline $\begin{array}{l}\text { Stockton } \\
\text { High School }\end{array}$ & $0.5 \%$ & $1.7 \%$ & $1.6 \%$ & $8.3 \%$ & $86.4 \%$ & $1.3 \%$ & $40.5 \%$ \\
\hline $\begin{array}{l}\text { Owensville } \\
\text { High School }\end{array}$ & $0.6 \%$ & $7.8 \%$ & $2.3 \%$ & $2.5 \%$ & $84.6 \%$ & $2.2 \%$ & $25.9 \%$ \\
\hline $\begin{array}{l}\text { Tallulah } \\
\text { High School }\end{array}$ & $3.5 \%$ & $0.7 \%$ & $1.8 \%$ & $3.4 \%$ & $89.3 \%$ & $1.4 \%$ & $37.6 \%$ \\
\hline
\end{tabular}

\section{Organizational Analysis}

Each of the five school districts within this study have the same basic structure:

school board, central office leadership, building level leadership, and classroom teachers and club advisors. Groups established around clients and product organizes each school district (Bolman \& Deal, 2013). In the case of the school system, the clients are the students, and the product is their learning. The various structural components, school leadership and personnel, work together to determine how best to help the client and produce a quality product. Each school district within the study can be analyzed through multiple organizational frameworks, including Mintzberg's (1979/2005) five basic parts 
of an organization, and Bolman and Deal's (2013) structural and human resource frameworks.

Mintzberg (1979/2005) organizes the five basic parts of an organization into the strategic apex, middle line, technostructure, support staff, and operating core. The diversity clubs researched in this study include school building-level leadership, principals and assistant principals, in the strategic apex. The building-level administration is overall responsible for the organization and are able to serve the needs of those who oversee the school happenings: the school board (Mintzberg, 1979/2005). Using this explanation, school principals are responsible for the organization as a whole, including student clubs, and report to the school board. A crucial part of the strategic apex is allocating resources and disseminating knowledge to employees (Mintzberg, 1979/2005). A large part of this study focuses on the allocation of resources to diversity clubs and the contribution of content and curriculum to advisors overseeing these clubs. Advisors overseeing diversity clubs are considered part of the operating core. They are responsible for securing the inputs (recruiting students for the club), transforming inputs into outputs (transforming students' knowledge about diversity), distributing the outputs (distributing knowledge about diversity to entire school), and providing support to the input, transformation, and output functions (aiding students in their multicultural education experiences and helping school leaders change school culture to be more inclusive) (Mintzberg, 1979/2005). The operating core, referring to the advisors, has a large influence on the overall production of a school's key clientele, the students. Each public high school within the Southwestern Wisconsin Conference included in this study has at least one diversity club and four of the high 
schools have two or more diversity clubs. This indicates the power of the operating core in securing input or student participation.

One of the assumptions of Bolman and Deal's (2013) structural framework is “organizations exist to achieve established goals and objectives" (p. 45). Analyzing each individual school district's goals and objectives as they relate to multicultural education and inclusion of diverse student populations is perhaps impossible to measure entirely. However, as a basis for this goal setting, we can assume the district has written goals related to educating students about diversity either in their school vision or mission statement, or district strategic plan. When researching each individual school, the following explicitly mentioned educating students about diversity: Centerville High School, Logan High School, and Highlandville High School. Not mentioning this intent in the mission or vision statement, or district strategic plan does not necessary mean the district does not strive for inclusion. However, for schools organizing student diversity clubs it is crucial employees are clear about what they are supposed to do or they will alter the goal to fit their personal preferences, thus not meeting the school district's presumed goals (Bolman \& Deal, 2013).

Bolman and Deal's (2013) human resource frame relates to the organizations within the study in several ways. School districts must hire the right people to fill the roles of diversity club advisors. Bolman and Deal (2013) recognize the importance of knowing what you want when hiring and being selective. One of the primary purposes of the study is to gather data regarding advisor qualifications and the selection process for these positions. Another facet of the human resource frame that relates to the study is empowering employees. One method of empowering employees is to provide them with 
information and support (Bolman \& Deal, 2013). Analyzing the various diversity clubs will allow the researcher to gather data about the support and information offered to the club advisor through administration support and professional development.

\section{Leadership Analysis}

The high schools within the study have the following building-level administration: Centerville High School, principal, associate principal, dean of students, and activities director; Logan High School, principal, associate principal, dean of students, and activities director; Highlandville High School, principal, two associate principals, and activities director; Stockton High School, principal, associate principal, and activities director; Owensville High School, principal, associate principal, associate principal/activities director; and Tallulah High School, principal, associate principal, and dean of students. Each diversity club within the study has at least one educator advisor who is considered the leader of the club. There is limited information about how many advisors are leading each club, the structuring of the club, and the names of those leading the club. However, each high school includes student organization and club offering lists on their website. The diversity clubs in each high school are as follows: School A: Amnesty International Club, Culture Club, Feminist Club, Gay-Straight Alliance, and Centerville Students United; School B: Gay-Straight Alliance and Understanding Cultural Differences; School C: Diversity Club and Gay-Straight Alliance; School D: International Cultures Club; School E: Spectrum Gay-Straight Alliance; and School F: International Club and Ho Chunk Youth Program. There are 13 identified clubs based on published information on school district websites. Aside from the listing of school building leadership, there is no published information about the role of the school 
building leadership and their interactions with diversity club advisors. Through the data collection process, the surveys and interviews will reveal details about the relationship between the building-level leadership and club advisors. The study will also be collecting data about leadership perspectives on advisor qualifications and resource availability, specifically professional development.

School leaders must strive for equity of educational opportunity as required by the Professional Standards for Educational Leaders (PSEL) (National Policy, 2015). These standards apply to all levels of educational leadership, including building level principals. Under standard three, school leaders must "promote the preparation of students to live productively in and contribute to the diverse cultural contexts of a global society" (National Policy, 2015, p. 11). Due to this standard and several others that allude to equity and inclusion of all students, high school principals within this study are concerned with issues of diversity within their schools and how to promote such inclusion. According to Levi (2014), successful and effective teams complete their task, maintain good social relations, and promote its members' personal and professional development. The study will be analyzing the availability of professional development as offered by the leadership of each high school. Professional development can be used as a form of organizational support. Leaders within each school will be surveyed about professional development offerings for advisors, as well as the selection process for club advisor roles. Levi (2014) believes an effective group must have the right people to perform the task. A focus of the study is advisor qualifications, therefore, building leadership will provide information about the selection process of diversity club advisors. To what extent a school leader supports a diversity club reflects their moral 
values of social inclusion (Leo \& Barton, 2006). School leaders must feel it necessary to promote inclusion within their school by supporting the diversity club and its leader.

During the study itself, the researcher will be utilizing a key leadership framework, Bass' transformational leadership (1985), to analyze the leadership of both the high school and student club. Bass' (1985) theory views transformational leadership as a process that focuses on organizational goals. The study will explore the perspectives of both the school administrator and diversity club advisor about the diversity club. School leadership must have a clear view of the overall purpose for the organization, the school, and the diversity club for the club to be successful (Bass, 1985). Gathering building-level administration and diversity club advisor perspectives will show the similarities and differences in goal setting for the diversity club.

\section{Implications for Research in the Practitioner Setting}

Each high school's emphasis on diversity and inclusion has led to the creation of a diversity club. Because time, resources, and personnel have been allocated to organize the club, each school would benefit from learning the results of this study. Results of this study can help the schools who have clearly defined increasing inclusion and expanding student knowledge about diversity as an organizational goal.

School leaders will be contacted in order to share findings of the study. The school leaders who will find this information useful are likely to be the administrators who directly oversee the happenings of the diversity club. Researcher Carlos McCray (2004) discusses the importance of principal buy-in if a school culture is in the process of changing to one that is considered more inclusive of diverse students. Principal leadership is especially valuable in the creation of diversity clubs because school leaders 
have both the authoritative power and ability to change school culture. School leaders can create an environment that is conducive for all student learning by promoting cultural competency (McCray, 2004). Also, school principals often make decisions related to their school building budget, including educator stipends and club funding. The results of this study will be useful in accessing and determining the needs of diversity clubs currently in place. School leaders can share the results of this study with other local principals who are contemplating starting a diversity club within their own high school.

Additionally, findings can be disseminated to the diversity club advisors at each high school. With limited research on the topics of diversity clubs, this will be particularly helpful to advisors dealing with opposition to the club or lack of support from other school faculty. Huerta (1999) provides an accurate, although dated, description of the lack of support for multicultural education as an inability of the organization to identify what multicultural education means to them and what they intend to teach. This study will add clarity to the discussions of how diversity clubs undertake multicultural education and what curriculum is taught.

Due to a lack of research about diversity clubs and advisor qualifications, resource allocation, and content and curriculum, any school with a diversity club would benefit from the findings of this study. In addition, school leaders pursuing academic research to support the creation of a diversity club will be able to read this study to support their decision-making process. Publications distributed to school leaders and diversity club advisors, such as Teaching Tolerance, could use this information to aid in the development of related clubs. As diversity club advisors and building principals seek out information regarding diversity clubs, frustration may set in due to the lack of 
academic research. By publishing this study in an academic journal visible to educators who emphasize multicultural education, they can gain specific knowledge about the various components of a diversity club, such as educator qualifications, resources, and curriculum.

\section{Summary}

The statistics presented in this section represent a growing trend of diversity within the U.S. and the state of Wisconsin. Cities, towns, and villages within the Southwestern Wisconsin Conference are experiencing these changes as well and are more diverse than ever before (Curtis, 2010). Diversity in the Southwestern Wisconsin Conference is most represented in its youth. One such example is the city of Lafayette has a total population of 52,109 with $4.85 \%$ of that population being Asian, while the student population attending the School District of Lafayette is almost 10\% Asian (U.S. Census, 2010).

Although the diversity within each school district varies, the basic organization and structure of the school districts within the Southwestern Wisconsin Conference are similar. The building-level leadership oversee the organization of the school and funding allocation. The advisors are responsible for organizing students and transforming student knowledge. The building principal leads the school and the advisor leads the diversity club. However, this study aims to identify in what specific ways the principals and advisors work together as leaders within the school building to help the organization achieve its established goals and objectives related to multicultural education and diversity. 
SECTION THREE:

SCHOLARLY REVIEW 
With the average American classroom exhibiting a continual increase of student diversity in ethnicity, race, socioeconomic status, gender, exceptionalities, language, religion, and sexual orientation, educators and school leaders have struggled to identify the best way to promote inclusion of diverse populations in a school setting. By the year 2020, researchers Patrick and Reinhartz (1999) claim one-half of all students in America will belong to a minority group. In many elementary classrooms, this minority majority has already occurred. As educators scramble to locate the key to successful implementation of a multicultural education program, students are left to the status quo of a classroom not cognizant of beneficial discourse about diversity.

The lack of research on multicultural education leads current researchers to rely on data from past researchers such as Huerta (1999) and Goodwin (1990). Although dated, the information presented is a helpful portrayal of multicultural education in schools. One such example of research is provided by Goodwin (1990), who states multicultural education classes can be effective but only when its various dimensions are clearly described, conceptualized, and researched by teacher-training institutions. According to Huerta (1999), "teacher educators themselves must be able to identify, differentiate and understand the basic concepts of multicultural education in order to provide instructional strategies to preservice teachers" (p. 1). This confidence in skill-set then must trickle down from professors to preservice teachers who become teachers in the classroom. Ultimately, multicultural education is effective when educators are knowledgeable about diversity in their classroom and are comfortable leading learning about cultural competency (Keengwe, 2010). The same has been discovered about the success of multicultural education programs school-wide; school 
leaders must be comfortable with discussions about diversity. These discussions are necessary if schools are to teach students about diversity, creating students who are able to embrace diversity as an ongoing "way of being" (Smith, 2016, p. 17).

My research will focus on multicultural education as it relates to diversity-related clubs. More specifically, what steps must be taken to effectively organize and lead diversity-related clubs. When researching diversity clubs, the club itself can take on many different names making the research a bit daunting. Regardless of the variance in names, it is common to see some form of a diversity club in today's schools. A common focus of diversity-related clubs is improving the relationship between straight and LGBTQ students, such as Gay-Straight Alliance Club. But diversity clubs are more farreaching than solely promoting the inclusion of LGBTQ+ students. Schools are also approving the creation of clubs to promote or support diversity in all forms, whether it is sexual orientation, race, socioeconomic status, ethnicity, gender, or any other area of diversity. These student organizations are necessary in leading whole school discussions about diversity, as discussion has been the common denominator in research about multicultural education that provides students with a meaningful learning experience (De La Mare, 2013).

This literature review will provide academic research conducted over the past fifteen years that acknowledges the importance of multicultural education. Additionally, it will show multicultural education can be taught successfully in the classroom and in student organizations such as diversity-related clubs. However, this success is contingent on researching and sorting through the limited research on multicultural education as it pertains to high school student organizations. 
The literature gap found in the research surrounds the necessary tools for a successful diversity club. Topics such as educator preparedness, resources for the advisor, and content or curriculum covered within the diversity club are heavily underresearched. To provide a stronger framework for diversity-related clubs, this literature review will present the purpose of diversity-related clubs, discuss educator preparedness in effectively leading a diversity club, identify resources needed to successfully support an advisor, and discuss content and curriculum that may perhaps lead to a more impactful student experience. For the purposes of this review, the phrase diversity club will be used in reference to any student organization or club whose purpose is to promote diversity and inclusion of any student group. With basic research lacking about diversity clubs' origins and goals, I believe the accumulation of the aforementioned topics is crucial in the continued development of diversity clubs at the high school level in an effort to change school culture and promote inclusion.

\section{Conceptual Framework}

Upon researching multicultural education, Banks' (1995b) multicultural education theory emerged as a natural fit for this study's conceptual framework. In addition to Banks' framework, Bass' (1985) transformational leadership framework will be utilized as a conceptual framework. Each framework is able to relate to the three guiding research questions of this study. The relationship between the two conceptual frameworks is also helpful in guiding the study and literary research supporting the study.

Banks (1995b) created five dimensions of multicultural education as a conceptual framework as his theory evolved from years of academic research. Banks' initial research focused on race and culture only, but with time extended the five dimensions to 
cover realms such as sexuality, religion, globalism (Cole \& Zhou, 2014, p. 111). These five dimensions include content integration, knowledge construction, prejudice reduction, equity pedagogy, and empowering school culture and social structure. Banks (1995a) asserted these dimensions "help theorists and researchers implement multicultural education in thoughtful, creative, and effective ways" (p. 1). Banks (1995a) described the gaps in literature as related to multicultural education and how these gaps lead to skepticism on the validity of multicultural education.

Further delving into Banks (1995b) multicultural theory, the first dimension, content integration, is the way in which educators use examples and content from various cultures when teaching key concepts within a subject area. Banks (1995b) asserted, when implemented correctly, "teachers can help students understand how knowledge is created and influenced by the racial, ethnic, and social-class positions of individuals and groups" (p. 1). The second dimension, the knowledge construction process, also entails conversations about perspectives and biases that may be constructed in knowledge (Banks, 1995b). According to Jay (2003), the purpose of multicultural education is to "move us towards the creation of concepts, paradigms, themes, and explanations that challenge mainstream knowledge, not help keep it in place” (p. 5). Multicultural education can spark conversations that lead to a reflective student body.

The third dimension of Banks' framework is prejudice reduction. Prejudice reduction of multicultural education "relates to the characteristics of students' racial attitudes and strategies that teachers can use to help them develop more democratic values and attitudes” (Banks, 1995b, p. 1). According to Banks (1995b), research surrounding prejudice reduction is vast but it is commonly found that before entering 
kindergarten, students of both color and white students have "white bias." The research shows it is imperative that educators, regardless of subject area, help students develop more democratic racial attitudes and values (Banks, 1995b). According to researchers Acquah and Commins (2013), "Teachers with a strong interest in and feeling for multiculturalism are often more successful in promoting the academic success of their learners" (p. 446). Prejudice reduction focuses on the power of the educator to aid students in overcoming established biases.

The fourth dimension in Banks' (1995a) multicultural theory is equity pedagogy. Equity pedagogy exists when educators modify teaching practices to promote the academic success of all students, regardless of race, ethnicity, culture, or gender group (Banks, 1995b, p. 1). Research suggests that students of color and low socioeconomic status will see gains in academic achievement when teaching strategies build upon the cultural and linguistic strengths of these diverse students (Banks, 1995b). Being able to teach the necessary content is an important part of being an educator but if an educator is unable to establish a connection with diverse students and create a meaningful learning experience, the educator's efforts are futile (Haberman, 2001).

Lastly, Banks described a school with an empowering school culture which views the school as a complex social structure. This dimension demands the entire school be viewed as one system and argues the system as a whole must be changed; not merely a few components (Banks, 1995b). School reform, in the form of complete restructuring, is ultimately the goal of this aspect of Banks's theory. 
The second conceptual framework is Bass' (1985) transformational leadership. According to Northouse (2016), transformational leadership is "a process that changes and transforms people" (p. 161). Transformational leadership is a process where leaders use their influence to transform their followers. In the case of diversity related clubs, advisors may act as transformational leaders when challenging the student participants to a higher level of motivation and morality (Northouse, 2016).

Bass (1985) argued that transformational leadership motivates followers to achieve more through three steps:

1. Raising followers' levels of consciousness about the importance and value of goals

2. Getting followers to transcend their own self-interest for the sake of the whole group

3. Moving followers to address higher-level needs

Specifically, Bass (1985) discussed intellectual stimulation as an important tenet of transformational leadership. Intellectual stimulation includes leadership "that stimulates followers to be creative and innovative and to challenge their own beliefs and values as well as those of the leader and organization" (Northouse, 2016, p. 169). Diversity related clubs draw awareness to the current values of the school and presumably challenge these viewpoints. Researchers Renn and Ozaki (2005) found that a reciprocal relationship between leadership and identity development of group members was highly emphasized in various studies. According to the same studies, the organization's leadership can also have a significant impact on the mission of the group (Renn \& Ozaki, 2005). Considering the impact of the diversity club advisor on the 
mission and participants of the club, transformational leadership allows a frame from which to view these possible leaders in the context of this study. Bass's (1985) ideas on addressing higher-level needs and raising followers' levels of consciousness also relates to Banks' multicultural education theory due to the similarities in raising student knowledge about values, goal setting, and overall higher level critical discussions.

\section{Purpose of Diversity Clubs}

With an increase in student diversity, discussions must occur to prevent discriminatory language and heighten student awareness about multicultural issues. Diversity clubs are a student-centered method to encourage these lessons and raise student awareness of the challenges that culturally diverse students face. In order to raise student awareness, educators and leaders must not only know how to host difficult dialogue through multicultural discussions but consistently establish multicultural education as a key goal of the school in an effort to "eradicate cultural tensions, low academic achievement, and high dropout rates" (Leistyna, 2001, p. 304).

Establishing a diversity club is an essential step in enhancing student awareness about diversity. Researchers Alejano-Steele et al. (2011) stated there "are not average students" (p. 92). They described how student populations are not comprised mostly of White, middle class students and therefore educators must be able to navigate curriculum in a way that appeals to all students. This quote also shows the significance of students becoming aware of their diverse peers. One example cited by Bomer, Dworin, and Semingson (2008) quoted sociologist Dennis Gilbert saying, "12\% of the United States population are 'underclass', 13\% are working poor, 30\% are working class" (p. 2503). The article described several other economic classes to support Bomer, Dworin, 
and Semingson's (2008) point that diversity appears largely in socioeconomic status in addition to race, ethnicity, and other diverse classifiers.

To promote a sense of unity when educating students about diversity, it is important the classroom not be the only opportunity for students to have difficult dialogue. Schools provide extracurricular activities that foster intergroup relations (Banks et al., 2001, p. 200). These extracurricular activities support the school's mission in educating students about diversity and provide students with extended learning time to delve deeper into conversations about diversity.

If school leaders firmly believe diversity is significant, extracurricular activities that educate students about diversity can be created. School leaders need to ensure the school climate is one where diversity is a central theme in the school (McCray, Wright, \& Beachum, 2004). School leaders need be also aware of their own personal beliefs as they directly influence professional beliefs (Brown, 2006, p. 704). When school leaders are able to establish the professional mentality that difficult conversations are crucial to student learning, clubs such as diversity club are able to flourish and provide even more opportunities for students to engage in difficult dialogue. Difficult dialogue leads to students and educators breaking the status quo where certain groups of students are alienated during the school day (Schoorman, 2010).

Diversity clubs are extracurricular opportunities that engage student in further difficult dialogue about multicultural issues they witness within and outside of their school building. Diversity clubs can also organize discussions that happen in the classroom during the school day. Preparation of educators leads to the hosting of difficult dialogue in a productive manner that contributes to student awareness and understanding 
about diversity. It is imperative that school leaders are willing to engage in "issues of inequity" and host difficult dialogue (Shields, 2009, p. 63). This literature review will discuss in further detail the importance of educator preparedness in leading multicultural instruction and the necessity of school leader support in doing so.

\section{Educator Preparedness}

In order for constructive conversations to occur in diversity clubs, educators must have ample opportunities to learn about diversity in their own collegiate experience (Denevi, 2006). How those learning opportunities appear, however, is based solely on the college or university's interpretation of creating a multicultural education curriculum. One method of enacting a curriculum inclusive of multicultural education is to receive Council for the Accreditation of Teacher Preparation (CAEP) accreditation through the National Council for Accreditation of Teacher Education (NCATE). CAEP accreditation standards were fully implemented in 2016 by NCATE. NCATE's goal is to establish high quality teacher preparation programs, and includes standards in diversity (NCATE, 2014). These standards target curriculum, field experiences, and clinical practices as opportunities for teacher candidates to develop skills and knowledge related to diversity. Of the 85 colleges and universities in Wisconsin alone, only seven institutions are accredited through NCATE (NCATE, 2014). Likewise, institutions sometimes struggle to meet the diversity standards, meaning that even when accredited they may not be ideal. Although NCATE represents only one method of university recognition of effective multicultural education experiences, there are a variety of other ways to include multicultural education. Regardless of the varying approaches to multicultural education in teacher preparation programs, research indicates that 
multicultural education is indeed necessary if teachers are to promote inclusion and support diversity in a school setting. The following researchers found that dialogue about diversity is integral in promoting inclusion at school.

Teacher education is a key ingredient to the successful implementation of discourse about diversity with students, whether it be in the classroom or in an afterschool student organization, such as a diversity club. Schoorman (2010) discovered in a study conducted about multicultural education conceptualizations among teachers that teacher education preparation programs are vital in preparing teachers for multiculturalism in their classroom. Schoorman (2010) stated professors need to shift from a pragmatic viewpoint on multiculturalism to a more realistic, authentic approach to teaching about possible scenarios that teachers may face as every classroom presents unique, diverse populations.

Researcher Jacque Ensign completed an eight-year study that evaluated multiculturalism in four different teacher education programs in an attempt to determine which programs were effectively preparing pre-service teachers for teaching in diverse settings. The data was analyzed after interviewing 35 teacher candidates that were currently enrolled in a B.A. education program at a Canadian university (Ensign, 2009). Ensign conducted two interviews with each participant and one observation of each participant; this data was then organized into 28 codes. Ensign's (2009) findings included an interested statistic on teachers reaching their students: "It is noteworthy that almost none of the student teachers from the nominal diversity teacher education programs mentioned the importance of knowing their students or mentioned readjusting their teaching to try to reach students who were not doing well in their classrooms" (p. 
172). This finding is indicative of how valuable pre-service learning is in evaluating one's own knowledge about poverty and diversity, and how poverty and diversity will impact student learning.

Another study conducted by Whiting and Cutri (2015) discovered the importance of offering even one multicultural education course in a preservice teacher's undergraduate study. Whiting and Cutri (2015) surveyed 175 respondents (24 male and 126 female). Participants were all pre-service educators, ranging from sophomores to seniors. Responses were organized into 239 codes (Whiting \& Cutri, 2015). In their findings, the typical White/European heritage pre-service teacher, after one 14-week class about multicultural education, was able to name privileges that advantaged their own lives (Whiting \& Cutri, 2015). However, their study also discovered that these participants would deconstruct their experiences of privilege by actively participating in service. For example, attending church resulted in rewards they viewed as a privilege. These same participants were unable to think critically about their own unearned privileges such as being white or speaking English as a first language (Whiting \& Cutri, 2015). Of their more significant findings, $29 \%$ of participants identified parent income as a privilege, $15 \%$ of participants recognized race as an unearned privilege, and $13 \%$ recognized education as an unearned privilege upon completion of the 12-week course (Whiting \& Cutri, 2015). Whiting and Cutri's (2015) suggested multicultural education courses should explore how unearned social privileges, such as language and citizenship, impact student learning. Unfortunately, many preservice teachers have not had the opportunity to assess their own personal biases. Ukpokodu (2002) stated teachers 
are required to know where students are in their own multicultural development in order to help expand their multicultural education knowledge. This self-examination is often limited to the confines of one multicultural education class and would best benefit students if woven into all classes (Zollers, et al, 2000).

Knowledge about diversity is a major factor that influences educator's attitudes towards students. Teacher understanding of cultural diversity and view on multicultural education as an integral part of regular instruction are crucial, and not just an addition (Acquah and Commins, 2013). Teachers strengthen an educational unit by organically fitting multicultural education into everyday lessons versus creating a unit focused on diversity that becomes a checklist item for completion. However, numerous studies have shown that teachers containing more than an excitement about the curriculum are considered effective multicultural educators.

Researcher Levine-Rasky (2001) conducted a study to identify indicators for teachers likely to implement multicultural education successfully in their classroom. In the study, 35 teacher candidates participated in at least two individual interviews. Findings were then organized into 28 codes that were divided into eight sections for qualitative data analysis (Levine-Rasky, 2001). Levine-Rasky's (2001) study discovered three specific indicators:

prospective multicultural educators personally identify with educational inequality or social injustice, prospective multicultural educators value critical pedagogy and multicultural education, and prospective multicultural educators desire to learn more about educational inequality and its causes including the 
social domination manifest in institutional racism and the practice of whiteness.

(p. 295)

Educators who exhibited these three traits were more likely to become agents for change regarding multicultural education and equity in education. Likewise, advisors as multicultural educators leading diversity related clubs might exhibit these same traits if they are to be successful.

\section{Necessary Resources}

One of the dominant struggles in education is the ever-lacking amount of resources available to educators. Educators are not always provided with sufficient professional development, supplies or funding within their classroom; this struggle can be more prevalent in the extracurricular world as these student activities are seen as "extras" added to the budget after consideration of necessary core teachings. Snellman, Silva, and Putnam (2015) stated, "While affluent and poor school districts alike have felt this pressure to trim their budgets, they have responded in markedly different ways. Poorer school districts often simply cut their extracurricular offerings" (p. 13). Considering the use of diversity clubs, one of the common factors influencing the success or failure of the club is a budget.

The prior section discussed the importance of teacher preparation programs in preparing educators for inevitable conversations surrounding multicultural education. However, significant learning can occur after an educator has secured a teaching or advisor role. Educators leading diversity clubs would benefit from two types of experiences: immersion in diverse settings and continued professional development. 
Educator ability in leading discussions about diversity is linked to educator preparedness and educator perception of their own ability to lead such conversations. Banks et al. (2001) stated, "Professional development programs should help teachers understand the complex characteristics of ethnic groups within the U.S. society" (p. 197). In order to lead discussions about diversity, educators are aware of different forms of diversity and how these different groups socialize within a school setting. A positive perception of one's own ability to teach is also considered valuable in teaching students about diversity. Gorski, Davis, and Reiter (2012) assert educators that have low levels of self-efficacy do not feel prepared to teach students about diversity. Gorski et al. (2012) described this low level of self-efficacy with a description from a study conducted by Assaf et al. (2010), in which the researchers found that "many of their teacher educator participants felt unsure about their abilities to prepare students to teach 'interculturally' because they did not feel adequately knowledgeable to do so" (p. 221).

According to researchers Acquah and Commins (2013), "Prospective teachers should be immersed in multiple cultural perspectives, particularly those of marginalized groups, to help them gain first-hand information that will challenge societal and preconceived stereotypes about people who are different from themselves" (p. 16). There is a gap in the literature about these experiences occurring after one becomes an educator. However, I believe this quotation is insightful as it argues first-hand experiences are crucial for educators to gain a true understanding of societal issues diverse persons face. 
Professional development is also a necessary resource and experience provided by the school to aid in educator understanding of multicultural education. Professional development and hands-on experiences in diverse cultures can and should go hand-inhand. According to Matherson and Windle (2017), "Successful professional development for teachers involves components of social interaction, not just the 'sit and get'” (p. 29). The researchers described how educators desire professional development that has hands-on practice of skills and strategies, and directly help students.

When applying these ideas to multicultural education, it can be argued educators benefit from professional development that provides direct hands-on experiences with diverse cultures and provides skills that can be directly applied to teaching students with diverse backgrounds. Cunningham, Etter, Platas, Wheeler, and Campbell (2015) contended "teacher knowledge and development may also be successfully constructed through relationship-based approaches" (p. 62). Building relationships with students of diverse backgrounds will create a more meaningful professional development opportunity, which in turn will benefit the advisor's role of leading multicultural education discussions.

In order to be successful, multiculturalism extends beyond professional development meetings. Researchers Denevi and Carter (2006) stated, "If multiculturalism is simply something that is added onto the curriculum, then both the educator and learner are less likely to be engaged in a process that will promote greater knowledge because underlying pedagogy remains unchallenged" (p. 19). They discovered professional development should be taught in a way that relates to the educator's everyday interactions with students and teaching practices do not transform 
when the work is being done away from their school settings. Allowing educators the time and space to explore multicultural education theory permits them to discover how it relates to their specific content and educational responsibilities.

One additional necessary resource to be considered when looking at effective diversity clubs is an appropriate budget. This budget could include an advisor stipend, funding for supplies, and funding for student experiences. If an educator is advising a student organization, such as a diversity club, a stipend may be necessary to gather qualified candidates for the position. A study conducted by Black (2016) stated, "The most qualified teachers, in particular, are the most sensitive to relative changes in salaries" (p. 1616). Ethically, qualified educators willing to take on an advisor role likely should be adequately paid to remain in the position.

Another financial resource consideration is the school district's allocation of funding for supplies and student experiences. According to Makina (2014), "In wellresourced schools, teachers are able to use a variety of practices that are challenging, rich and aligned to learner needs, but in poor environments the choices are limited" (p. 299). In a school district with properly funded student organizations, groups such as a diversity club will be able to provide more opportunities for their students because they have the necessary resources and supplies.

Kronholz (2012) contended there is no ready estimate about how much districts spend for extracurriculars. However, districts account for various factors in different ways. Teacher after-school pay, bus transportation, and if students are charged for participation are often documented differently. Although data on budgeting for such clubs is nonexistent, research stated, "There is a link between after-school activities and 
graduating from high school, going to college, and becoming a responsible citizen" (Kronholz, 2012, p. 5). Without school funding, diversity clubs may become obsolete, thus limiting the number of civic-minded extracurricular offerings to students within a high school setting.

\section{Content and Curriculum}

In direct relation to Banks' (1995b) multicultural education framework, this section will focus on the content and curriculum covered in diversity clubs. Multicultural education researcher Nisivoccia (1995) stated, "A culturally coherent multicultural curriculum is a curriculum that is diverse in its make-up...has a sense of a large, compelling purpose, and actions are tied to that purpose" (p. 4). The hope of a multicultural curriculum is to form a learning environment that is accepting of an increase in cultural diversity. Those who support a multicultural education believe the traditional curriculum systematically excludes people of color and women from gaining equitable educational opportunities (Nisivoccia, 1995). Diversity clubs contribute to the schools' purpose of promoting inclusion of diverse student groups and therefore should have a curriculum inclusive of people of color. Schools can be an ideal place for students to explore topics of race and identity because "schools are controlled environments.

Schools function as laboratories for teaching students how to act and interact with people of other races-training for the real world" (Davis, 2007, p. 210).

Diversity club advisors have the ability to create a curriculum that is inclusive of all diverse students. Banks (1995b) described the modification of teaching in ways that will facilitate the academic achievement of students from diverse racial, ethnic, cultural, and gender groups as "an equity pedagogy" (p. 4). Curriculum is often a beginning step 
in a total school transformation towards an empowering school culture (Banks, 1995a). Banks' (1995a) multicultural education theory finds curriculum to be an imperative step in empowering a school building. Students can create an accepting community within their school by questioning their feelings about different races.

Davis (2007) asserted schools that allow students to write or share about stereotypical perceptions of their own race and other races are more likely to then have conversations dispelling these myths. Through dialogue, students can break down social tensions. Davis (2007) described the type of curricular material that should be utilized in multicultural education settings as "accurate and balanced" (p. 212). Educators can use multicultural curriculum to promote positive understanding about diverse populations. However, the material should be accurately presented and it is best to use diverse educational materials such as films, plays, novels that represent members of all groups.

Due to the literature gap on curriculum within a diversity club, it is challenging to find the necessary resources that help guide the lessons and discussions within a diversity club. One of the primary teaching resources available to diversity club advisors is Teaching Tolerance. Teaching Tolerance is an organization sponsored by the Southern Poverty Law Center and provides a vast collection of materials for educators. This collection was created with the intention to "support the efforts of teachers in addressing important diversity and equity issues in their classrooms" (Henry \& Rios, 2013, p. 338). The resources available include: teaching kits, films, posters, lesson plans, ideas for activities, periodical magazine, etc. With a focus on equity, justice, and respect, Teaching Tolerance is a prime resource for a diversity club advisor. This is the only free 
and easily accessible curriculum resource discovered during research for multicultural education as it relates to diversity clubs.

\section{Summary}

This review is important to future studies because it provides sources that support the idea of difficult dialogue and multicultural education. Future studies need to be conducted specifically about diversity clubs and their effectiveness in promoting dialogue about inclusion and diversity. With increasing diversity in schools, it is crucial educators are knowledgeable about all forms of diversity and able to promote diversity, contributing to a positive school culture.

The research surrounding extracurricular resources indicates educator pay does indeed have an impact on advisor participation. However, there is little research on other financial considerations related to clubs such as diversity clubs. Research related to supplies and funding supports the idea they are necessary, however there is no monetary amount designated to the successful implementation of such clubs.

However, the research provided does include specific support regarding educator qualifications and curricular decisions. Educators require an innate desire to be multicultural educators. Exposure to diversity and meaningful experiences in diverse settings is also crucial in considering qualifications. Professional development, similarly, needs to be meaningful and engaging. Research also supported multicultural education curriculum that focused on acknowledging cultural differences, debunking cultural stereotypes, and engaging students in difficult dialogue regarding diversity and inclusion. Both Banks' multicultural education theory and Bass' transformational leadership theory 
help frame research surrounding multicultural education and promoting diversity and inclusion as a school leader.

This literature review provides information relevant to multicultural education but also indicates the lack of obvious research surrounding diversity clubs. There is a major literature gap related to diversity club educator qualifications, resources, and curriculum. Although research can be found relating to each of these categories, it is limited in number and not very thorough. Scholarly practitioners interested in diversity clubs as a method of promoting inclusion and diversity will continue to have a difficult time establishing the characteristics of either a successful and unsuccessful diversity club until further research is conducted. 
SECTION FOUR:

CONTRIBUTION TO PRACTICE 


\section{Author's Note}

The researcher plans to submit this piece to Teaching Tolerance magazine. The submission guidelines for this magazine state the submission should be a feature story that must be between 800 and 1,600 words. This magazine feature generally appeals to classroom educators, counselors, and administrators and contains resources, how-to steps, or short profiles. 
Entering the classroom as a first-year teacher, I was a 22-year-old with vision; a vision for the layout of my classroom, the exceptional units on To Kill a Mockingbird I would prepare, and the life lessons I would teach that would hopefully alter the trajectory of my students' lives. But as I walked through the metal frame of my classroom door about three weeks into my teaching career, I realized my personal frame would have to shift. One of my roles within the high school was journalism advisor, which entailed teaching journalism and leading two extracurricular clubs: yearbook and newspaper. As a journalism advisor, I felt responsible for incorporating multicultural education lessons into both the classroom and extracurricular experiences. I wanted to produce student journalists who could articulate the cultural impact of the current events they were reading and writing about. Although I appeared confident in front of my students, I did not feel equipped to lead these lessons. I spent countless hours researching and seeking professional development to determine best practices in organizing a curriculum, activities, and even the physical structure of my classroom to accommodate students. I found myself questioning how to lead difficult dialogue that encouraged student growth, specifically as it pertained to diversity and inclusion.

School leaders have been encouraging educators to promote cultural competence both in the classroom and in extracurricular learning opportunities because research conducted over the past two decades indicates a positive relationship between diversityrelated extracurricular activities and changes in student knowledge, discourse, and awareness (Cole \& Zhou, 2014). However, educators often do not feel equipped to lead these extracurricular activities because they feel unsure of their knowledge of teaching 
interculturally. Furthermore, there is very little research on how to prepare educators to lead diversity-related student clubs. In addition to limited research, there are significant literature gaps when researching what resources, such as professional development and funding, are most helpful to support the advisor in her role, and what curriculum and lessons would empower students to become culturally competent. The apparent literature gap on diversity-related clubs and my personal path as an educator inspired the topic selection of my dissertation, which centered on diversity-related clubs and advisor qualifications, club resources, and multicultural curriculum. The purpose of my study was to encourage discussion on such topics and to provide insight from advisors and principals currently leading diversity-related clubs.

My study was conducted in a rural Wisconsin school conference comprised of six public high schools. Five of the high schools participated in the study. Participants included at least one advisor and one principal from each school. The total student population of the participating schools was approximately 5500 high school students. The data collection process included a survey with five questions and a follow-up interview with each participant lasting approximately 25 minutes. Participants' names and school names were assigned pseudonyms to encourage more transparent reflections.

\section{Advisor Preparedness}

To promote a positive school culture that embraces cultural differences, it is important the classroom is not the only place that encourages difficult dialogue about diversity; schools must provide extracurricular activities that foster intergroup relations (Banks et al., 2001, p. 200). To lead these extracurricular activities, educators need to have had access to multicultural education courses in college as such courses are vital in 
preparing teachers for multiculturalism in their classroom (Schoorman, 2010). Three of the six educators in my study had four or more collegiate classes centered on multicultural education. Yet only one participant strongly agreed that they were confident in their knowledge of multicultural education and diversity, indicating collegiate courses focused solely on multicultural education alone did not lead to sufficient participant confidence with multicultural education. Based on this study's findings, school leaders may not need to focus on advisor qualifications to appoint advisors best-suited for the role. Participants in the study alluded to several other key factors that influenced their success, including resources and professional development.

\section{Providing Resources and Professional Development for Club Advisors}

Several club advisors and school principals indicated that no resources were given to the advisor as they began or continued an established diversity club, while others described the provided resources as outdated and irrelevant. Several advisors identified specific resources they found helpful in leading students. One participant said, "Over the years, the local university has been a huge resource for us and we have a relationship with them. They host high school student diversity events so we can coordinate taking students there and recruit other students from cultural literature class to attend as well." The local university was mentioned in other interviews as a place to find diversitycentered workshops for both students and educators. The university diversity and equity offices were also named as resources.

Organizations and local non-profits in close proximity to the school were also identified as resources. Several organizations were specifically designed to meet the needs of diverse populations in that region, thus allowing diversity club advisors to utilize 
their services and materials to educate students. For example, a participating school belongs to a community where a specific Native American tribe is prominent. This participant's school asks leaders of the tribe to come into the school and share different traditions they have. The school also hosts a powwow to give these Native American students the opportunity to share their culture.

Local non-profits often reflect the diverse needs of a highly individualized community. One club advisor utilizes resources provided by a local non-profit organization that promotes advocacy, programming, and outreach regarding the LGBTQ+ community. This non-profit organization has readily available materials for public educators. Other location-specific resources are governmental agencies and military bases. The conference where this study took place is near a military base. The military requires monthly diversity activities and because of this, a school close to this base has been able to utilize the mandated activities as a resource for both students and the club advisor. The club advisor stated, "We are able to glean off of the fort's investment in their diversity. They facilitate or organize a speaker or panel or something that relates to the monthly focus." The advisor continued his description of various speakers, such as a colleague of Martin Luther King Jr., who educated students on issues of racial inequality and diversity.

School leaders were interviewed regarding resources as well. The principals interviewed identified funding challenges as a problem for all clubs, not just diversity clubs. Although two of the five principals stated there are limited professional development opportunities for advisors, one principal mentioned, "We typically do a half day of diversity professional development. That may not sound like a lot but that is one- 
tenth of our professional development focused on diversity and equity." Club advisors identified the lack of professional development as a frustration within their advisor role. One advisor said, "I know my co-advisor would agree with me. I wish we could go to a day symposium to get ideas on how to make the club better and more active." As lack of funding is a prevalent problem in education, seeking local resources can be key if funding is limiting professional development opportunities for club advisors. Contacting local non-profit organizations, military bases, and other educational institutions can allow an under-resourced diversity club to gain the following: the expertise of persons trained extensively on diversity and inclusion, materials for the club's activities, and professional development opportunities for advisors.

\section{Curriculum for Diversity Club}

Both principal and advisor feedback on curriculum was very specific to the individual purpose of that club. However, three key findings emerged from questions pertaining to curriculum: there is no set curriculum, students are highly engaged in the curriculum, and the curriculum should reflect the needs of the school.

All six of the club advisors stated they did not have a set curriculum. One advisor hopes to develop a curriculum because "the club is pretty informal and students are coming for the social aspect more than anything." Although lacking a curriculum can create a sense of informality, four of the advisors in the study stated the lack of a teacherprovided curriculum allowed student participants to create a curriculum, resulting in higher levels of student engagement. An interviewed principal said the diversity club "must be student-interactive and focused on the issues they are most concerned about." Advisors and principals are finding value in allowing the club to be student-led because 
the students are most in sync with the needs of the main stakeholder of the group: the students.

The success of many of these diversity clubs seems to be the collaboration occurring between the club advisor and his/her students. One club advisor explained, "We work together to devise what we would like to present and discuss with our officers what students want to do and how it would work." With this collaboration, club advisors have relied on help from students to recruit other students. Students have also reached out to surrounding schools' diversity clubs to brainstorm new ideas for diversity activities at their school. A club advisor explained student engagement as "something they are proud of."

Because diversity can appear differently in each community, there is no "one size fits all" solution for how to construct a diversity club. However, it is important to determine what needs the diversity club must address within the individual school. To address these needs, one club advisor stated, "It is important to evaluate the diversity within your school to understand what different groups and what different diverse populations are in your school to start with. If you see a need to educate your students on a specific group or people, identify how to recognize them." Diversity club advisors and school leaders might meet to discuss the goals of the club, as well as how the club can provide value to the entire school. Also, diversity club advisors struggling to organize curriculum can rely on student insight to determine what lessons and activities would best fit the goals of the club. 


\section{Conclusion}

It is my hope that this article sharing an exploratory study in an under-researched area stimulates discussion among teachers, administrators, students, parents, and policy makers to better prepare, resource, and support the growing prevalence and mission of diversity clubs. 


\section{References}

Banks, J. A., Cookson, P., Gay, G., Hawley, W. D., Irvine, J. J., Nieto, S., \& Stephan, W. G. (2001). Diversity within unity: Essential principles for teaching and learning in a multicultural society. Phi Delta Kappan, 83(3), 196.

Cole, D., \& Zhou, J. (2013). Do diversity experiences help college students become more civically minded? Applying Banks’ Multicultural Education Framework. Innovative Higher Education, 39, 109-121.

Schoorman, D. (2010). Conceptualizations of multicultural education among teachers: Implications for practice in universities and schools. Teaching and Teacher Education, 26(4), 1041-1048. 
SECTION FIVE:

CONTRIBUTION TO SCHOLARSHIP 


\begin{abstract}
With increasing numbers of diverse students in the public-school system, educators are attempting to meet the needs of these students incorporating multicultural curriculum into the mainstream classroom and extracurricular activities. While there is significant research conducted on multicultural education, there is very little research on how to best prepare educators to lead student organizations related to diversity. This mixed-methods case study was conducted to gain principal and diversity club advisor insight into the organization of high school diversity clubs. The data collected was derived from five public high schools in a southwestern Wisconsin conference, and included eleven participants. The focus of the study was specifically on advisor qualifications, club resources, and multicultural curriculum, which was accomplished through two data collection methods: online surveys and interviews. The surveys were analyzed using descriptive quantitative analysis and the interviews were coded with in-vivo methods. In addition to the intended three themes, four emergent themes were identified. This study discovered advisor qualifications were not a clear factor in diversity clubs. When reflecting on what tools were necessary to feel prepared to lead a diversity club, participants placed emphasis on financial resources, curriculum, and professional development. School building administration also mentioned resources, professional development, and collaboration as key factors in promoting diversity within their school's diversity clubs.

Keywords: diversity club, advisor qualifications, professional development, funding, multicultural curriculum
\end{abstract}


Case Study of Diversity Clubs:

Advisor Qualifications, Club Resources, and Multicultural Curriculum

In the fall of 2014, the National Center for Education Statistics (2017) discovered in the White students enrolled in public schools comprised less than 50\% of the student population. As communities and school leaders brainstorm specific strategies to meet the needs of all students, multicultural education has become a central focus on these conversations. One of the emerging ideas has been the idea of a diversity-related club, organized with and/or by students and led by a faculty member. Such clubs have been witnessed under various names, such as multicultural clubs, diversity clubs, or GayStraight Alliances. The purposes of these student clubs are to promote inclusion through difficult dialogue and student involvement. Limited research over the past two decades demonstrates a positive relationship between diversity related curricular activities, such as diversity clubs, and civic outcomes, such as change in knowledge and discussion (Cole \& Zhou, 2014). While there is significant research conducted on multicultural education, there is very little research on how to best prepare educators to lead diversity clubs.

\section{Literature Review}

Diversity clubs are student-centered and allow for extracurricular opportunities to host difficult dialogue regarding the challenges that diverse students face. With increasing diversity in schools, researchers have recognized "there are not average students" (Alejano-Steele et al., 2011, p. 92). To promote discussions about these differences, diversity clubs offer opportunities to alter the status quo through difficult dialogue, thus furthering relations between alienated student groups and their peers 
(Schoorman, 2010). In valuing diversity, school leaders often support such efforts due to the intergroup relations that are forming (McCray, Wright, \& Beachum, 2004).

In order for discussions with diversity clubs to be constructive, educators should have had opportunities to learn about diversity during college (Denevi, 2006; Schoorman, 2010). One study conducted by Whiting and Cutri (2015) discovered that even a single offering of a multicultural education course in a teacher candidate's undergraduate study allowed educators to more aptly name their own privileges when considering their own lives. But one class is insufficient to promote rich understanding of the diverse needs of students and multicultural education is more beneficial if woven into all classes to some degree (Zollers et al., 2000).

In addition to diversity knowledge, "how to" is also crucial. Levine-Rasky (2001) conducted a study that identified indicators for teachers likely to successfully implement multicultural education. Educators who personally identify with educational inequality or social injustice, value critical pedagogy, and desire to learn more about educational inequality and institutional racism were more likely to be agents for change. Arguably, club advisors, are more likely to be successful if they exhibit the same traits.

In addition to knowledge and know how, club advisors must be given sufficient resources to ensure success, an ongoing concern in education. In poorer school districts, extracurricular activities are seen as extras and often lose funding first (Makina, 2014; Snellman, Silva, \& Putnam, 2015). Limited funding can also influence the quantity and quality of professional development opportunities awarded to educators. Banks et al. (2001) stated professional development programs should be available to educators to help them understand the complex makeup of ethnic groups in the United States. Without 
professional development, educators often feel a low sense of self-efficacy and do not feel prepared to teach students about diversity. A study conducted by Assaf, Garza, and Battle (2010) found many teacher educator participants did not feel qualified to teach inter-culturally because they did not feel adequately prepared. For educators not feeling very satisfied with professional development offerings, research has shown the normal "sit and get" is simply not providing adequate skills and strategies to encourage greater feelings of self-efficacy (Matherson \& Windle, 2017). For professional development to be successful, it should be engaging and taught in a way that relates to the educator's everyday interactions with students (Denevi \& Carter, 2006).

Club advisors also are concerned with the funding for student experiences, supplies, and potential stipends. The research on funding for diversity clubs is nonexistent. However, research does indicate that there is no one-specific amount on how much districts spend on extracurricular activities (Kronholz, 2010). Kronholz (2010) determined that there is a link between participating in after-school activities and one becoming a productive, responsible citizen. Thus, limiting extracurricular offerings due to funding could eliminate diversity clubs as a possibility for developing civicmindedness in the broader population.

Curriculum covered in diversity clubs is another responsibility of club advisors. Nisivoccia (1995) believed coherent multicultural curriculum had to have a compelling purpose and all actions must be linked to that purpose. Banks (1995b) described this curriculum as "equity pedagogy" (p. 4). Multicultural education theory finds curriculum crucial in empowering students and faculty at a school. A multicultural education 
curriculum allows for difficult dialogue, and, through this dialogue, students can dispel myths about their own race and other races (Davis, 2007).

\section{Conceptual Framework}

This study utilized two different conceptual frameworks: Banks's (1995b) multicultural education theory and Bass' (1985) transformational leadership framework. Banks's theory has evolved over years of academic research. Initial research focused on race and culture alone, but, over time, the framework has grown to cover diversity issues, such as sexuality, religion, and globalism (Cole \& Zhou, 2014). Through this research, Banks created five dimensions to help theorists and researchers successfully implement multicultural curriculum. These dimensions are as follows: content integration, knowledge construction, prejudice reduction, equity pedagogy, and empowering school culture and social structure. Bass's (1985) transformational leadership involves a process that changes people. He believed that transformational leadership motivates followers to achieve more through the subsequent three steps: raising followers' levels of consciousness about the important and value of goals, getting followers to transcend their own interest for the sake of the whole group, and moving followers to address higherlevel needs. Bass (1985) also discussed the idea of intellectual stimulation as a major component of transformational leadership. One method of intellectual stimulation is for leadership to encourage followers to be creative, and challenge the beliefs and values of the organization, its leaders, and themselves (Northouse, 2016). Transformational leadership is a framework to build willingness to challenge the status quo through difficult dialogue. Diversity club advisors are orchestrating such dialogue through the curriculum and goals of their clubs. Bass' (1985) transformational leadership and Banks' 
(1995b) multicultural education theory place emphasis on student knowledge acquired through challenging conversation.

\section{Purpose of the Study}

The purpose of this study was to organize research and provide guidelines in the following areas: advisor qualifications, resources for advisor (including professional development), and content and curriculum for diversity related student organizations. This foundational research will aid in further research that can delve into each aspect of the diversity club.

\section{Research Questions}

The research questions that guided this study were:

1. In regard to preparation of educators to lead diversity clubs, what qualifications do these advisors hold?

2. In what ways, if any, does building administration provide these advisors with resources to aid in the establishment and future endeavors of the student organization?

3. What content and curriculum is used to guide extracurricular instruction and activities?

\section{Methods}

\section{Participants}

A southwestern Wisconsin conference is the setting for this study due to the proximity of the location to the researcher. This conference is comprised of six public high schools and one private high school. Participating schools have similar population sizes and student demographics. The private high school did not have a diversity club 
and was therefore omitted prior to the start of the study. One of the public high schools did not wish to participate. Six advisors and five building administrators participated in the study out of a possible thirteen participants. This study had a response rate of $83 \%$. Participating schools and individual participants were assigned pseudonyms to ensure confidentiality.

Participants for this study included an educator advisor, and an assistant principal or building principal from each school. The total student population represented in this study was approximately 5500 students. Table 1 provides an overview of the ethnicity and free/reduced lunch rates of the high schools included in the study. [Insert Table 1 Here]

To guide the selection of what was considered a diversity club, the researcher utilized the Wisconsin Department of Public Instruction’s (DPI) (2017) nondiscrimination policy for athletics and activities. According to the DPI's standards, all diversity clubs appearing in the study are considered school sanctioned. The DPI has also implemented a Culturally Responsive Education program to prepare each student for cultural responsiveness in the real world, specifically in the areas of race, language, and culture. Diversity clubs appearing in this study were examined based on titles of the club, mission statements, and club activities to determine if the club focused on multiple cultures. Clubs, such as Gay-Straight Alliance, whose mission statements discuss racial, gender, LGBTQ and economic justice were included in the study because the diversity discussed reached multiple diverse student populations. Clubs focusing on one sole culture, such as Fellowship of Christian Athletes, were omitted because religion is not 
encompassed in the DPI's Culturally Responsive Education program guidelines and the club focuses on one culture.

\section{Procedure}

Data collection included three different strategies: advisor surveys, principal surveys, and semi-structured interviews with all participants. The combination of principal and club advisor- participants in both the survey and interview data collection processes, and the recognition of emerging themes aided in triangulation (Creswell, 2014). All data were coded to keep participant names and school names confidential. Survey respondents did not identify themselves in their responses, and interviews were coded to ensure confidentiality.

The first data collection method was a survey that included both qualitative and Likert scale quantitative questions. The expectation of highly individualized responses influenced the researcher to select a qualitative, interactive phenomenological approach to the study. Interactive phenomenological studies focus on the experiences of several individuals who have experienced the same phenomenon (Creswell, 2014). The advisor surveys included two central questions and eight sub-questions. Four of the questions were qualitative and six of the questions were structured as Likert scale questions. Principal surveys included three qualitative questions. The researcher then conducted interviews with each participant to provide additional insight not acquired through the surveys. The interview responses were vital in providing insight into the lived experiences of both club advisors and principals. The phenomenological approach strengthened these insights because it focuses on personal experiences and the individual's perception of that experience (Smith \& Osborn, 2008). Follow-up questions 
were also asked, if necessary, to provide clarification of these lived experiences during the interview process.

Data analysis included in-vivo coding of interview responses to keep intact the actual words and phrases spoken by the study's participants (Creswell, 2016). The coding process began with identifying which responses fell into the key themes. Key themes included: advisor qualifications, resources (professional development and funding), and multicultural curriculum. As interviews were transcribed and participants identified important ideas about the diversity club, emergent themes were added to the list of themes. These emergent themes were indicative of shared experiences and similar perceptions of those experiences. Emergent themes included: collaboration, student-led activity, inclusion, and challenges. The researcher used descriptive statistics, specifically frequency distribution charts, were created to summarize quantitative data that was exploratory and did not seek to prove a relationship between multiple factors.

\section{Findings}

Themes related to the following categories were anticipated prior to the beginning of the study based on the focus of the study: (a) advisor qualifications, (b) club resources (professional development and funding), and (c) multicultural curriculum. However, four emergent sub-themes developed throughout the surveys and interviews: (a) providing resources through community collaboration, (b) student-led curriculum, (c) focus on inclusion, and (d) isolation presents challenges to advisors.

\section{Theme A: Advisor Education as a Key Qualification}

The category advisor qualifications refers to the qualifications an advisor exhibits or lacks when leading a diversity club. These qualifications may include, but are not 
limited to, certification, undergraduate education in multicultural education, and years of experience in education. When asked about collegiate classes taken on multicultural education, $50 \%$ of advisor-participants had taken three courses, while $33.3 \%$ had taken two courses and $16.7 \%$ had taken one course. Despite the variance in multicultural courses taken, all six advisors felt confident in their knowledge of multicultural education.

Aside from the quantitative questions asking for the specific number of collegiate courses taken dedicated to multicultural education and years of teaching experience, only one study participant, a principal, mentioned advisor qualifications in the entire study. This participant stated, "The experience they have is not always a key factor; passion working with students is more important than their experience." This principal indicated they did not place emphasis on advisor education as a qualification. The data in this category was few in number. No additional sub-themes developed related to advisor qualifications.

\section{Theme B: Club Resources: Professional Development and Funding}

Participants highlighted professional development opportunities offered and funding provided by their school districts to aid in the development of both the teacher and the diversity club itself. When asked about resources, one of the six participants mentioned they are not compensated for their advisement role. Three of the six advisorparticipants felt the professional development offerings to advisors was inadequate or very inadequate, while three advisor-participants felt the offerings were somewhat adequate. 
Participants discussed professional development opportunities that were offered to all staff during in-service training days and professional development that they individually sought to provide specific guidance in leading a student club. Although professional development was mentioned repeatedly throughout the study, few participants had gone to professional development training for advising a club or discussing diversity with students. One participant stated, "My co-advisor and I have been teaching for a while and we feel there is a limited opportunity for such development so we don't pursue them." For participants who have pursued professional development, oftentimes that event was offered in-house. For example, one principal explained, "We typically do a half day diversity PD [professional development] day. A half day PD day does not sound like much but over the course of five total PD days, that is one-tenth of our PD focused on diversity and equity." This same principal stated, "If it was specific to the group, it would be unlikely they would get professional development because we don't pay for PD for coaches, advisors, or otherwise." Another principal's response supported the lack of professional development offerings: "Currently our district has not put a lot of focus on the professional development for the advisors...Specifically, to the diversity club, we would have a hard-pressed time giving professional development to that club. Instead, we would focus on the big picture for the school." Principals discussed funding as the main reason why professional development was difficult to offer on an individual basis. Another principal elaborated, "Everybody wants an assembly or professional development, but how can we get it there and at an equal rate?"

Funding was discussed as provided either by the school or through fundraising. Participants discussed the limitations in funding or benefits of funding. Four of six 
participants felt resources, including funding, were inadequate to some degree. One participant voiced frustrations with the current funding process reliant on fundraising as, "If you want to do a fundraiser, where do you get the funds to start a fundraiser? If you don't have the funds, the students don't feel appreciated and don't feel important." A second advisor stated frustration, "The club has never been funded. We definitely are not the only club that is not funded. Probably about half." Although funding limitations were discussed, five advisors felt funding did not limit the club's activities. One advisor explained, "I guess we don't have an issue with funding, or lack thereof. If there was an outside expectation put on us and it was not something supported financially, that would be an issue but that has not been an issue up to this point." Another advisor stated, "We fortunately have enough in savings that we don't have to do a ton of little things all the time." The principals mirrored these responses. An additional idea provided by one principal was the creation of a positive student account for club funding. He said, "It was made for any positive student activities that can better school culture. It is our parking lot fund. Whatever we get from selling parking lot passes. That gives us some money to do positive things for our school." He then explained how that fund paid for several of the diversity club's events.

Subtheme 1: Providing resources through community collaboration. Several participants also mentioned collaboration as a resource, thus creating a sub-theme of collaboration. Collaboration was discussed in reference to relationships between advisors and clubs and reaching out to other community groups and other schools' diversity clubs. The following advisor explained an example of collaboration as, "This year we were finally able to connect with other schools and their clubs. The students are going to meet 
and interact." Another diversity club advisor described collaboration with a diversity club advisor from a neighboring school district: "A former coworker of mine works in the Lafayette School District and although we have different demographics of students, we can still apply the same ideas." Connections with local public secondary schools was identified as one of many local resources.

Several participants mentioned local organizations, educational institutions, and non-profits as resources for the diversity club. One participant mentioned the local university as a resource stating, "The local university has been a huge resource for us and we have a relationship with them. They would host high school student diversity kind of events so we would coordinate taking students there." Another participant discussed the help provided by a local non-profit organization, which provided resources concerning LGTBQ+ students. Yet a third participant mentioned Teaching Tolerance, a magazine organized by the Southern Poverty Law Center, as a written resource because "the suggested activities are organized, and they also provide materials you can use to publicize your events." A fourth participant highlighted the regular seminars of a local military base, in which the students participated.

\section{Theme 3: No set curriculum}

All participants discussed curriculum and lessons that their diversity club integrated into the club meetings. Curriculum varied in what lessons were provided and to whom. In several cases, the curriculum and learning activities extended beyond the club and was organized for the entire school or for a traditional classroom setting. The following response is indicative of all advisor responses: “As a club, we don't have a 
curriculum." Without a set curriculum, the subsequent subthemes are crucial in providing insight into what curriculum and lessons are evident in diversity clubs.

Subtheme 2: Student-led curriculum. Student participants create the curriculum that is organized within the diversity clubs, and the club itself is often studentled. Each club advisor described the curriculum as student-driven. Even the recruitment process is student-led, as shown in the following advisor quote: "I did not really recruit students; our club is so student-led. You have to have a group that really wants to do it for it to fall in place." One principal stated, "The club should be student-interactive; what are the issues they are most concerned about."

Subtheme 3: Focus is inclusion. Advisors and principals discussed inclusion as a primary goal of the diversity club. A few advisor responses regarding inclusion included: "If you see a need to start a diversity club, if you have people that you need to educate the student population about and how to recognize them, that's a place to start," and "Even if they have a club...no other extracurricular, at least they can do that one thing that they are proud of." The participating principals alluded to lessons of inclusion. One principal stated, "We hope students are taught lessons of inclusion and accepting other cultures."

Subtheme 4: Isolation presents challenges to advisor. The last subtheme focuses on challenges advisors identified when organizing a diversity club. Advisors expressed several challenges, including the recruitment of students, lack of resources and payment for advising, and getting staff on board with the club's goals. One advisor answered, "I think one of the challenges is getting all of your staff on board. We have these signs that say this is a safe space. So, we pass those out to teachers at the beginning 
of the year to show students support. And there are still teachers who say 'nah'." Another advisor explained the culmination of feelings as, "It is kind of isolating. I do sometimes wonder if I am doing it correctly? Should I be more involved?”

\section{Discussion}

Numerous findings from this study support the ideas of multicultural education and the value of diversity clubs. Schoorman (2010) found that multicultural education in teacher education programs is vital in preparing teachers for multiculturalism in their classrooms. However, advisors indicated that they were not all "adequately prepared" to deal with multiculturalism in the classroom due to lack of preparation prior to becoming a teacher or professional development once they are in the classroom. The results support teacher education prior to entering the advisor role alone is not the key factor in advisor preparedness.

This study's findings indicate the key factor in educator confidence when leading and organizing diversity clubs stems from appropriate resourcing. Advisors recognized specific resources and collaboration found in their community, whether it from the local university, other club advisors, or online sources focused on diversity. Providing adequate resources for diversity club advisors is crucial. Such resourcing includes appropriate funding for the club. Although most clubs were self-sustaining, funding was necessary for educational opportunities for club members. Funding methods varied greatly from school to school, which supports Kronholz's (2012) study that there is no specific estimate on how much districts pay for extracurricular activities.

Banks' (1995b) multicultural education theory was evident in each diversity club's focus on inclusion. Every diversity club advisor indicated that the curriculum was 
student-led, and this was supported by each building principal's response as well. When considering the third dimension of Banks (1995b) multicultural education theory, prejudice reduction, students and advisors worked together to create learning activities that related to students' racial attitudes to develop more democratic attitudes. David (2007) believed schools that allow students to share about stereotypical perceptions of race are more likely dispel myths about race and break down social tensions. The schools within this study are allowing students to share on topics of diversity in an effort to break down social tensions. They value student input in curricular decisions because they believe students will select discussion topics and activities that most appropriately meet the needs of the school's diverse student populations; thus, allowing the club to be "student interactive." Student leadership in discussion topics and activities to meet the needs of the high school also supports Bass' (1985) transformational leadership by allowing followers to transcend their own self-interest to benefit the whole school. Both the advisors and students filled leadership roles within the diversity club.

\section{Limitations and Future Research}

One of the limitations of this study was determining which clubs to include in the study. Diversity clubs take on various names to address the varying diversity within the school in which they are implemented. Gathering background knowledge with which to frame survey and interview questions was challenging due to the variance in terms. Future research should be conducted with these study's key themes to discover if the same themes emerge in other school conferences implementing diversity clubs. Another limitation of this study was not all eligible schools and persons decided to participate. One school within the conference declined participation. There were also other diversity 
clubs within several of the participatory schools who either had advisors unwilling to participate or principals who preferred to only include one diversity club in the study. Ideally, future research would include a larger sample of diversity clubs within each building.

A third limitation was the data collection process relied heavily on interviews, which can provide a limited perspective. Although interviews allowed in-vivo coding, which allows researchers to gain direct participant perception, those perceptions can be limited or biased (Creswell, 2016). Further research could focus on comparing the various factors that impact a diversity club to show relationships with these factors, including specifying, assessing, correlating, or experimenting to determine markers of effectiveness. For example, additional research could determine if there is a relationship between the advisor's choice of curriculum and the students' perceptions of the club's effectiveness in promoting inclusion.

A delimitation of this study was the focus on one school conference. The perimeters established for this study allowed the researcher to conduct a study in an unfamiliar area in a timely manner. However, for future research, a study needs to be expanded beyond one school conference in Wisconsin and should be conducted in multiple school conferences simultaneously. Another delimitation was this particular study was designed to organize foundational information about diversity clubs, not to find correlates, predictors, or mediating variables, or to assess comparative effectiveness. As another example, additional research could gauge student interest in and perceptions of school inclusion after implementing a diversity club. 


\section{Recommendations}

The fact that advisor qualifications were scarcely mentioned in participants' responses supports the idea that the resources available to educators are perhaps more significant in increasing educator confidence in teaching multicultural curriculum. Each participant revisited the topics of funding and professional development multiple times as a major influence on their perceived success, or lack of success, as a diversity club advisor. For educational leaders, evaluating what resources are given to diversity club advisors is crucial in determining if diversity club advisors feel supported in their role and feel able to provide students with meaningful activities when attending club meetings. Educational leaders need to evaluate the funding of extracurricular activities and determine how budgets can be assigned fairly. The study also points out the value of in-house professional development about diversity and equity, which allows benefits not only diversity club advisors in their roles, but educates the entire staff.

Advisors with limited funding must be creative in their approach to resourcing. Collaboration with local universities and non-profit organizations were mentioned as ways to find resources for reduced costs. Diversity club advisors seeking more student participation can also rely on their passionate club members to recruit more students. Club advisors can rely on these same students to determine what curriculum will benefit diverse student populations and students wishing to become more culturally competent.

For community members involved in promoting inclusion of diverse populations of people collaboration with local K-12 schools is crucial in creating a community culture that embraces diversity. Community members affiliated with non-profit organizations, universities, and other local organizations with a mission to educate others about 
diversity, reaching out to the local schools and sharing relevant resources and services will help support advisors with scarce resources. 


\section{References}

Alejano-Steele, A., Hamington, M., MacDonald, L., Potter, M., Schafer, S., Sgoutas, A. \& Tull, T. (2011). From difficult dialogues to critical conversations: Intersectionality in our teaching and professional lives. New Directions for Teaching and Learning, 125, 91-100. doi: 10.1002/t1.436

Assaf, L. C., Garza, R., \& Battle, J. (2010). Multicultural teacher education: Examining the perceptions, practices, and coherence in one teacher preparation program. Teacher Education Quarterly, 37, 115-135.

Banks, J. A. (1995b). Multicultural education: Its effects on students' racial and gender role attitudes. In J. A. Banks \& C. A. M. Banks (Eds.). Handbook of research on multicultural education (pp. 617-627). New York: Macmillan.

Banks, J. A., Cookson, P., Gay, G., Hawley, W. D., Irvine, J. J., Nieto, S., \& Stephan, W. G. (2001). Diversity within unity: Essential principles for teaching and learning in a multicultural society. Phi Delta Kappan, 83(3), 196.

Bass, B. M. (1985). Leadership \& performance beyond expectations. New York, NY: Free Press.

Cole, D., \& Zhou, J. (2013). Do diversity experiences help college students become more civically minded? Applying Banks’ Multicultural Education Framework. Innovative Higher Education, 39, 109-121.

Creswell, J. W. (2014). Research design: Qualitative, quantitative, and mixed methods approaches (4th ed.). Los Angeles, CA: Sage.

Creswell, J. (2016). 30 Essential skills for the qualitative researcher. Los Angeles, CA: Sage. 
Davis, J. R. (2007). Making a difference: How teachers can positively affect racial identity and acceptance in America. Social Studies, 98(5), 209-214.

Denevi, E., \& Carter, R. (2006). Multicultural seminar: A new model for professional development. Multicultural Perspectives, 8(2), 18-24. doi:10.1207/s15327892mcp0802_4

Kronholz, J. (2012). Academic value of non-academics. Education Digest, 77(8), 4-10. Levine-Rasky, C. (2001). Identifying the prospective multicultural educator: Three signposts, three portraits. Urban Review, 33(4), 291-319.

Makina, B. (2014). Re-sourcing of resources: an investigation into student teachers' manipulation of resources in disadvantaged teaching contexts. African Identities, 12(3/4), 295-313. doi:10.1080/14725843.2015.1009617

Matherson, L., \& Windle, T. M. (2017). What do teachers want from their professional development? Four emerging themes. Delta Kappa Gamma Bulletin, 83(3), 2832.

McCray, C. R., Wright, J. V., \& Beachum, F. D., (2004). An analysis of secondary school principals' perceptions of multicultural education. Education, 125(1), 111-120. National Center for Education Statistics. (2017). The condition of education. Retrieved from https://nces.ed.gov/programs/coe/indicator_cge.asp

Nisivoccia, J. D. (1995). A district-wide multi-cultural high school curriculum. Retrieved from https://files.eric.ed.gov/fulltext/ED421555.pdf

Northouse, P. G. (2016). Leadership: Theory and practice. Thousand Oaks, CA: Sage Schoorman, D. (2010). Conceptualizations of multicultural education among teachers: 
Implications for practice in universities and schools. Teaching and Teacher Education, 26(4), 1041-1048.

Smith, J. \& Osborn, M. (2008). Interpretative phenomenological analysis. In Smith, J. (Ed).

Qualitative Psychology: A practical guide to Research Methods (pp. 53-80). London, England: Sage Publications.

Snellman, K., Silva, J., \& Putnam, R. (2015). Inequity outside the classroom: Growing class differences in participation in extracurricular activities. VUE, 40, 7-14.

Whiting, E. F., \& Cutri, R. M. (2015). Naming a personal "unearned" privilege: What pre-service teachers identify after a critical multicultural education course. Multicultural Perspectives, 17(1), 13-20. doi:10.1080/15210960.2014.984717 Wisconsin Department of Public Instruction. (2017). Wisconsin report cards. https://dpi.wi.gov/accountability/report-cards

Zollers, N. J., Albert, L. R., \& Cochran-Smith, M. (2000). In pursuit of social justice: Collaborative research and practice in teacher education. Action in Teacher Research, 22(2), 1-14. 
Table 1

Comparison of Ethnicity and Free/Reduced Lunch Rate of High Schools Within the Study

\begin{tabular}{|c|c|c|c|c|c|c|c|}
\hline \multirow{2}{*}{$\begin{array}{c}\text { High Schools } \\
\text { Within }\end{array}$} & \multicolumn{6}{|c|}{ Percentage of Students of Various Ethnicities } & \multirow{2}{*}{$\begin{array}{l}\text { Percentage of } \\
\text { High School }\end{array}$} \\
\hline & American & Asian or & Black or & Hispanic & White & Two & \\
\hline Southwestern & Indian or & Pacific & African & & & or & Population \\
\hline Wisconsin & Alaska & Islander & American & & & more & Eligible for \\
\hline \multirow[t]{2}{*}{ Conference } & Native & or Native & & & & races & Free/Reduced \\
\hline & & Hawaiian & & & & & Lunch \\
\hline Centerville & $0.8 \%$ & $8.5 \%$ & $3.9 \%$ & $3.2 \%$ & $78.4 \%$ & $5.1 \%$ & $37 \%$ \\
\hline \multicolumn{8}{|l|}{ High School } \\
\hline Lindberg & $0.64 \%$ & $12.34 \%$ & $5.53 \%$ & $3.73 \%$ & $71.59 \%$ & $6.17 \%$ & $48.59 \%$ \\
\hline \multicolumn{8}{|l|}{ High School } \\
\hline Highlandville & $0.5 \%$ & $8.2 \%$ & $1.2 \%$ & $0.8 \%$ & $87.5 \%$ & $1.8 \%$ & $27.4 \%$ \\
\hline \multicolumn{8}{|l|}{ High School } \\
\hline Stockton & $0.5 \%$ & $1.7 \%$ & $1.6 \%$ & $8.3 \%$ & $86.4 \%$ & $1.3 \%$ & $40.5 \%$ \\
\hline \multicolumn{8}{|l|}{ High School } \\
\hline Owensville & $0.6 \%$ & $7.8 \%$ & $2.3 \%$ & $2.5 \%$ & $84.6 \%$ & $2.2 \%$ & $25.9 \%$ \\
\hline \multicolumn{8}{|l|}{ High School } \\
\hline Tallulah & $3.5 \%$ & $0.7 \%$ & $1.8 \%$ & $3.4 \%$ & $89.3 \%$ & $1.4 \%$ & $37.6 \%$ \\
\hline High School & & & & & & & \\
\hline
\end{tabular}


SECTION SIX:

SCHOLARLY PRACTITIONER REFLECTION 


\section{Influence of the Dissertation on Practices as an Educational Leader}

As I approach the end of this doctoral journey, I reflect back on experiences that occurred prior to the orientation of this program. When I was 16-years-old, I created a bucket list of specific goals I wished to accomplish. I remember looking at that list, which is kept in my wallet, while sitting at my desk during my second year of teaching. That list contained an item I am now almost able to officially check as completeobtaining my doctoral degree in educational administration. I was continuously telling my students, especially my female students, to aim high, and develop and mature your leadership skills. To set a positive example for my students and to honor my 16 -year-old self's desire to accomplish the highest possible accolade in education, I applied for the University of Missouri Ed.D. Cohort Program.

Beginning the program, I had my sights set on high school administration. At the time, I felt my few years of experience and master's degree in educational leadership had properly equipped me for a principal position. However, I now realize the opportunity I had for personal and professional growth as I entered my first doctoral class. Through the program's challenging coursework and difficult dialogue, I was able to gain new depth of knowledge and feel much more confident in my ability to be a school leader.

Reflecting on the dissertation process is hard in isolation as the program collectively had a large impact on my knowledge as an educational leader. Thus, this reflection will incorporate knowledge gained through the doctoral program which came to fruition in the dissertation process. The following advice was given to my fellow cohort members and me: We should continually think, talk, read, and write when in doubt about our individual progress within the program. This advice was referred to 
often as I pondered how to navigate the dissertation process. The dissertation process challenged me to access knowledge gained two years prior to the actual writing of the dissertation. I found myself trying to recall author names and organizational analysis theories that we had not discussed in months. I was excited to discover that the knowledge gained throughout coursework steadily and consistently found its way back to my thought processes and were able to be transferred to paper in the writing of the dissertation. When in doubt and when my own knowledge failed me, I found myself reaching out to cohort classmates to talk about helpful sources about diversity and multicultural education. By thinking, talking, and writing, I have matured my knowledge as an educational leader.

The specific knowledge I have gained as an educational leader through the dissertation process relates to diversity and multicultural education. The interview process during data collection was the most enlightening. Throughout the Ed.D. program, I gathered new terminology and theories relevant to educational leaders that allowed me to speak with other educational leaders as if I was "part of the club." The data collection process built upon this new knowledge and also built my confidence by reaffirming what I had already learned in the program. Coming from a limited diverse background, I was eager to familiarize myself with the language of multicultural educators. During data collection interviews, I was able to frame my questions with fluent wording while accurately referring to multicultural education resources. I also was able to interpret interviewees' responses and quickly ask follow-up questions based on this familiarity. However, I also gained new wisdom about diversity and multicultural education during the interview process. I gained awareness about local programs that 
supported diverse student populations. I gained insightful leadership advice from school principals on the challenges of promoting diversity within a public high school setting. Lastly, I gained understanding about how best to support a school culture that is inclusive and accepting of diverse persons.

Aside from acquiring knowledge, the dissertation process provided me with new skill-sets. I felt confident in my research and interviewing skills upon entering the program but like so many other areas of this program, I quickly realized just how much I had to learn. The dissertation process allowed me to strengthen my research and interviewing skills in ways that will benefit my career as an educational leader, as is shown in the following paragraphs.

The research required in the literature review and practitioner setting sections of the dissertation were challenging due to the complexity of my topic. The research available on diversity clubs is almost nonexistent. This created many frustrating nights of research during the literature review process and I had to find research on an array of related topics to compile meaningful information. However, the information I did find was helpful as an educational leader because now I know where to look for this information in my future roles in high school administration and how to interpret this information to apply to the context of my position. Identifying journal articles and other academic research that discuss diversity clubs or multicultural education curriculum will have a positive impact on the teachers and club advisors I will lead in the future, as I will be able to provide resources and professional development regarding diverse student populations and help them explore how to apply the research in a way that creates more resources to utilize. 
The interviewing skills developed through the dissertation process will also benefit my role as an educational leader by strengthening my ability to communicate and ask timely and difficult questions. I find myself engaging in difficult dialogue with colleagues more often, specifically when they are discussing challenges of educating diverse learners. One such example was when a colleague was uncomfortable with modifying a summative assignment for a child with a learning disability and individualized education plan. I asked this colleague a series of questions that required reflection on her reasons behind not wanting to provide modifications. This conversation was uncomfortable to have and could easily have come across as judgmental, but with my strengthened interviewing skills I feel I have the tools and sensitivity to ask hard questions in a delicate and appropriate manner. The interview process was initially challenging for me due to the hard questions I had to ask persons in superior positions to myself. However, I quickly realized that the hard questions were not so hard for these professionals. Reflecting on their ease in answering my research questions, I now realize educational leaders are accustomed to receiving and asking hard questions themselves. Interviews gradually become more conversational and follow-up questions became more natural throughout the data collection process. I believe the interview process prepared me to ask and receive difficult questions that are part of the everyday role as a building principal.

The dissertation process allowed me to strengthen my knowledge and skills as an educational leader. I am grateful I completed this program at the time in my life at which I did. I was hesitant to start a doctoral program with limited leadership experience because I was afraid I would not have much to contribute in the way of discussions. 
However, I found I could bring a different perspective to discussions as an emerging school leader. I also feel the timing of my experience in this program was helpful in building my confidence to apply for assistant principal positions and encouraging me to try new positions within each of my last three job postings within the field of public education. I can confidently say that each step of the dissertation process, from the literature review to the submission-ready journal articles, allowed me to strengthen my resume for larger leadership roles, my knowledge of diversity, and my resolve to lead a school with the most inclusive methods possible.

\section{Influence of the Dissertation on Role as a Scholar}

I felt confident going into this program that embracing the practitioner aspect of this program would feel very natural. I was quickly able to build connections between the journal articles and topics of discussion to my own experiences as a classroom teacher and school leader. However, I was excited about the prospect of developing skillsets as a scholar. My previous graduate work helped me to find value in becoming a scholar but I feel as though the doctoral experience aided in honing those skills, specifically in the areas of research and data analysis.

To prepare for the academic research required when writing a dissertation, I had to review methods of quantitative and qualitative research. I reviewed various textbooks to remind myself of best practices in qualitative research, in particular Creswell's (2014) Research Design: Qualitative, Quantitative, and Mixed Methods Approaches. One of the most significant personal gains I have experienced through writing a dissertation is the scholarly knowledge I have gained and the ability to quickly reference various scholarly texts to aid in my own research. 
Because my study was heavily focused on qualitative research, I had to spend the majority of my time reviewing interview questioning approaches. Trying to keep the integrity of the participant's answers intact, I decided to use in-vivo coding. To ensure that participants were comfortable with the interviewing process and that their answers were authentic I was especially careful in the wording of my questions. Interview questions were open-ended and not leading in the hopes that answers would be true to each person's personal experience. I also tried to keep interviews slightly conversational to create a level of rapport and comfort during the process. Each of these decisions was made after reflecting on best research practices as outlined through the coursework's' texts and discussions.

In preparation for the quantitative portion of my study, I reviewed the best ways to create quantitative survey questions. Likert scale questions were utilized to allow participants to select the answers that best suited their opinions. The assigned coursework readings allowed me to make these scholarly decisions; I do not feel as though I was equipped prior to this part in my academic career to make research design decisions. I feel much more comfortable with quantitative research, specifically in designing Likert scale questions due to the dissertation writing process. The revision processes in place involving committee members were also vital in building my comfort levels with quantitative research. The feedback I received in all areas, especially the survey questions, strengthened my survey questions and made me reflect on the caliber of the questions I intended to use. Without this feedback, my questions would have potentially not produced the same responses within the study. 
The dissertation process provided me with opportunities to become more confident as a scholar, specifically with APA formatting and conducting research. I was able to practice formatting text, tables, and graphs in APA format. Writing correct in-text citations and reference pages almost seems second-nature now as I have had ample time to practice. Oftentimes during the writing process, I did not have to refer to the APA guidebook as I had it partially memorized. This skillset will be particularly helpful as I continue my practice as a scholar. I also have more confidence in my research skills. I can confidently navigate academic search engines and wade through numerous journal article abstracts, quickly accessing which are relevant to my own research and which are not. The significance of journal abstracts is now apparent after conducting my own research; they provide a glimpse of the purpose of the study. Entering the literature review phase of my dissertation, I found the research process daunting. Now, I am able to exercise the practice of abstract reading and key word identification to maneuver through databases more efficiently.

When reflecting on the data analysis process, I was most leery to begin work with my quantitative data. As a prior journalism teacher and active writer, I found qualitative research more naturally enjoyable because I am passionate about hearing the voice of others in words. The analysis aspect of quantitative research was worrisome, especially due to my lack of confidence with SPSS. Even accessing the program itself was a challenge. To conquer these particular fears, I had to rely heavily on online tutorials published by various educational institutions. Once I was reminded of how to run descriptive analysis, I was able to recall the steps we learned during summer two of the program. My quantitative questions were limited in number as my research was 
qualitative-heavy in nature, and I still feel anxious with the prospect of doing far more challenging processes with SPSS, such as regression. However, I feel as though forcing myself to incorporate some quantitative data in my research allowed me to independently practice what I had learned about statistical analysis and encouraged me to push myself as a scholar. I now find value in both methods of research and can recognize the strength of having both within a research study; mixed method studies allow for participant voice but also provide straightforward responses that are easily interpreted.

Perhaps the most significant realization I have had during the dissertation process is that I truly enjoy conducting research and I enjoy the scholarly facet of this program almost equally to the practitioner facet. In fact, I have been begun looking at jobs at the university level. I realize my interests are no longer limited to the PK-12 world, and I may be able to apply these new skillsets to higher education. I am looking specifically at leadership roles within a university or entry-level education professor positions similar to that of an adjunct. I am still interested in serving as a high school principal, but I am not opposed to a career in higher education. I recently applied for a high school assistant principal position at a local high school. I believe graduation from this program will aid in my ability to secure an interview due to the educational leadership theories, practices, and experiences provided through the coursework and dissertation process. Working as an assistant principal would allow me the opportunity to focus on applying research to a PK-12 practitioner role. However, my interests are now more varied and working at the university level would allow me to continue conducting academic research and even continue my own research. To build upon this study, I could conduct additional research on the student perceptions of diversity clubs. Specifically, a follow-up study could focus 
on the curriculum students perceive to be the most beneficial to their peers. Another study could focus on principal perceptions of school culture before and after diversity clubs are organized within a public high school setting. With limited research on diversity clubs, there are many directions additional research could travel, which is exciting to think about as a scholar.

\section{Summary}

As an educational leader, the dissertation process was enlightening as it allowed me to continue develop new ideas on inclusion, diversity, and school leadership. Through the processes of thinking, talking, and writing, I can find application in almost every academic journal article. I know feel better equipped to read and interpret data presented in such articles and if unable to do so, I am familiar with resources to aid in interpretation. The dissertation process also permitted me to see the value of relying on others' strengths. From my peers to committee members, each carries a unique set of perspectives and skillsets. The dissertation process allowed me to recognize these individuals as resources for both the research conducted throughout my study, and for future application as a scholar or practitioner.

Because my research focused multicultural education, I gained new terminology and theoretical knowledge related to diversity and inclusion. In professional settings, this acquired information has been helpful in speaking language of the "in group." I feel part of the club, as has been described by many peers. This feeling alludes to the ability to enter a conversation with an educational leader and being able to hold one's own in discussion through clear articulation of theory and practical example. However, increased awareness of theory and practitioner examples is more significant than just 
spouting off a few facts; this awareness can transform the experiences of the teachers I lead in the future. I can apply what I have learned and offer more relevant professional development and resources for teachers in the areas of multicultural education, diversity, and inclusion.

From a scholarly perspective, I was able to practice interviewing, research, and data analysis skills, which allowed me to apply best practices learned throughout the program's coursework. Familiarity with SPSS will be useful if my research continues in various follow-ups to this study. Feedback from committee members was crucial in forming relevant and direct quantitative survey questions. Yet again, through committee member feedback, I was able to recognize the importance of relying on the expertise and individual strengths of academics to accomplish the task at hand. With this feedback, I was able to improve my study's methods and analysis, thus building my confidence as a scholar and encouraging me to pursue careers outside of the PK-12 realm. In reflection, each experience throughout the dissertation process lead to the interweaving of two roles: scholar and practitioner. 


\section{References}

Acquah, E. O., \& Commins, N. L. (2013). Pre-service teachers' beliefs and knowledge about multiculturalism. European Journal of Teacher Education, 36(4), 445-463. doi:10.1080/02619768.2013.787593

Alejano-Steele, A., Hamington, M., MacDonald, L., Potter, M., Schafer, S., Sgoutas, A. \& Tull, T. (2011). From difficult dialogues to critical conversations: Intersectionality in our teaching and professional lives. New Directions for Teaching and Learning, 125, 91-100. doi: 10.1002/t1.436

Armstrong, D. G., Henson, K. T., \& Savage, T.V. (2001). Teaching today: An introduction to education (6th ed.). Upper Saddle River, NJ: Merrill Prentice Hall.

Assaf, L. C., Garza, R., \& Battle, J. (2010). Multicultural teacher education: Examining the perceptions, practices, and coherence in one teacher preparation program. Teacher Education Quarterly, 37, 115-135.

Astin, A. W. (1993). What matters in college? San Francisco, CA: Jossey-Bass.

Banks, J. A. (1995a). Multicultural education and curriculum transformation. Journal of Negro Education, 64(4), 390.

Banks, J. A. (1995b). Multicultural education: Its effects on students' racial and gender role attitudes. In J. A. Banks \& C. A. M. Banks (Eds.). Handbook of research on multicultural education (pp. 617-627). New York: Macmillan.

Banks, J. A., Cookson, P., Gay, G., Hawley, W. D., Irvine, J. J., Nieto, S., \& Stephan, W. G. (2001). Diversity within unity: Essential principles for teaching and learning in a multicultural society. Phi Delta Kappan, 83(3), 196. 
Banks, J. A. (2013). The construction and historical development of multicultural education, 1962-2012. Theory into Practice, 52(sup1), 73-82. doi:10.1080/00405841.2013.795444

Banks, J. (2001). Cultural diversity and education: Foundations, curriculum, and teaching. Needham Heights, MA: Allyn and Bacon.

Bass, B. M. (1985). Leadership \& performance beyond expectations. New York, NY: Free Press.

Bell, D. (1975). Ethnicity and social change. Cambridge: Harvard University Press.

Black, D. W. (2016). Taking teacher quality seriously. William \& Mary Law Review, 57(5), 1597-1669.

Bolman, L. G., \& Deal, T. E. (2013). Reframing organizations: Artistry, choice, and leadership. (5th ed.). San Francisco, CA: Jossey-Bass.

Bomer, R., Dworin, J., May, L., \& Semingson, P. (2008). Miseducating teachers about the poor: A critical analysis of Ruby Payne's claims about poverty. The Teachers College Record, 110(12), 2497-2531.

Brown, K. M. (2006). Leadership for social justice and equity: Evaluating a transformative framework and andragogy. Educational Administration Quarterly, 42(5), 700-745. doi: 10.1177/0013161X06290650

Caddo Gap. (2017). Author guidelines for multicultural education magazine. Retrieved from http://www.caddogap.com/download/guidelines.pdf

Cole, D., \& Zhou, J. (2013). Do diversity experiences help college students become more civically minded? Applying Banks’ Multicultural Education framework. Innovative Higher Education, 39, 109-121. 
Creswell, J. W. (2014). Research design: Qualitative, quantitative, and mixed methods approaches (4th ed.). Los Angeles, CA: Sage.

Creswell, J. (2016). 30 Essential skills for the qualitative researcher. Los Angeles, CA: Sage.

Cunningham, A. E., Etter, K., Platas, L., Wheeler, S., \& Campbell, K. (2015).

Professional development in emergent literacy: A design experiment of teacher study groups. Early Childhood Research Quarterly, 31, 62-77.

Curtis, K. (2010). Census 2010 Chartbook: Demographic trends in Wisconsin. Retrieved from http://www.apl.wisc.edu/publications/2010_census_chartbook_wi.pdf

Davis, J. R. (2007). Making a difference: how teachers can positively affect racial identity and acceptance in America. Social Studies, 98(5), 209-214.

De La Mare, D.M. (2013). Dialogue across lines of difference: Acknowledging and engaging diverse identities in the classroom, Communication Teacher, 27(2), 7175.

Denevi, E., \& Carter, R. (2006). Multicultural seminar: A new model for professional development. Multicultural Perspectives, 8(2), 18-24. doi:10.1207/s15327892mcp0802_4

Ensign, J. (2009). Multiculturalism in four teacher education programs: For replication or transformation. Multicultural Perspectives, 11(3), 169-173.

doi:10.1080/15210960903116928

Field, A. (2013). Discovering statistics using IBM SPSS statistics (4th ed.). Los Angeles, CA: Sage.

Fink, A. (2013). How to conduct surveys: A step-by-step guide (5th ed.). Los Angeles, 


\section{CA: Sage.}

Gates, G. J. (2011). How many people are lesbian, gay, bisexual, or transgender? http://williamsinstitute.law.ucla.edu/wp-content/uploads/Gates-How-ManyPeople-LGBT-Apr-2011.pdf

Goodwin, L. (1990). Foundational Studies in Teacher Education. New York: Teachers College Press.

Gorski, P. C., Davis, S. N., \& Reiter, A. (2012). Self-efficacy and multicultural teacher education in the United States: The factors that influence who feels qualified to be a multicultural teacher educator. Multicultural Perspectives, 12(4), 220-228. doi: $10.1080 / 15210960.2012 .725332$

GSA Network. (2009). Our approach. Retrieved from https://gsanetwork.org/about-us Haberman, M. (2001). The creation of an urban normal school: What constitutes quality in alternative certification? Educational Studies, 32(3), 278.

Henry, L., \& Rios, C. (2013). Using teaching tolerance resources to prepare future teachers. NAAAS \& Affiliates.

Huerta, G. C. (1999). Barriers to the implementation of multicultural education in a secondary teacher preparation program. High School Journal, 82(3), 150.

Jason, M. H. (2000). The role of the principal as transformational leader in a multicultural learning community. High School Journal, 83(3), 1.

Jay, M. (2003). Critical race theory, multicultural education, and the hidden curriculum of hegemony. Multicultural Perspectives, 5(4), 3-9. 
Keengwe, J. (2010). Fostering cross cultural competence in preservice teachers through multicultural education experiences. Early Childhood Education Journal, 38(3), 197-204. doi:10.1007/s10643-010-0401-5

Kronholz, J. (2012). Academic value of non-academics. Education Digest, 77(8), 4-10.

Leistyna, P. (2001). Extending the possibilities of multicultural professional development in public schools. Journal of Curriculum \& Supervision, 16(4), 282.

Leo, E., \& Barton, L. (2006). Inclusion, diversity, and leadership. Educational Management Administration and Leadership, 34 (2), 167-180. doi: $10.1177 / 1741143206062489$

Levine-Rasky, C. (2001). Identifying the prospective multicultural educator: Three signposts, three portraits. Urban Review, 33(4), 291-319.

Makina, B. (2014). Re-sourcing of resources: an investigation into student teachers' manipulation of resources in disadvantaged teaching contexts. African Identities, 12(3/4), 295-313. doi:10.1080/14725843.2015.1009617

Marshall, P. L. (1995). Misconceiving multicultural education. Education Digest, 60(7), 57.

Matherson, L., \& Windle, T. M. (2017). What do teachers want from their professional development? Four emerging themes. Delta Kappa Gamma Bulletin, 83(3), 2832.

McCray, C. R., Wright, J. V., \& Beachum, F. D., (2004). An analysis of secondary school principals' perceptions of multicultural education. Education, 125(1), 111-120. 
Mintzberg, H. (2005). The five basic parts of the organization. In J. M. Shafritz, J. S. Ott, \& Y.S. Jang (Eds.), Classics of organizational theory (6th ed., pp. 219-230). Boston, MA:

Wadsworth. (Reprinted from The structure of organizations: A synthesis of research, pp. 18-34, 1979, Saddle River, NJ: Prentice-Hall)

National Center for Education Statistics. (2015). Digest of education statistics 2015. Retrieved from https://nces.ed.gov/pubs2016/2016014.pdf

National Center for Education Statistics. (2017). The condition of education. Retrieved from https://nces.ed.gov/programs/coe/indicator_cge.asp

National Policy Board for Educational Administration. (2015). Professional Standards for Educational Leaders 2015. Reston, VA.

NCATE. (2014). Accredited institutions by state. Retrieved from http://www.ncate.org/tabid/177/Default.aspx?ch=106\&state=wi

Nisivoccia, J. D. (1995). A district-wide multi-cultural high school curriculum. Retrieved from https://files.eric.ed.gov/fulltext/ED421555.pdf

Northouse, P. G. (2016). Leadership: Theory and practice (7th ed). Thousand Oaks, CA: Sage

Patrick, D., \& Reinhartz, J. (1999). The role of collaboration in teacher preparation to meet the needs of diversity. Education, 119, 388-399.

Race Bridges for Schools. (2007). Race relations seeking harmony. Retrieved from racebridges.net

Renn, K. A., \& Ozaki, C. K. (2005). Student leaders in identity-based campus contexts. Paper presented at the annual meeting of the Association for the Study of Higher 
Education, Philadelphia, PA.

Ryan, F., Coughlan, M., \& Cronin, P. (2007). Step-by-step guide to critiquing research: Part 2: Qualitative research. British Journal of Nursing, 16(12), 738-744.

Schoorman, D. (2010). Conceptualizations of multicultural education among teachers: Implications for practice in universities and schools. Teaching and Teacher Education, 26(4), 1041-1048.

Seidman, I. (2013). Interviewing as qualitative research: A guide for researchers in education and the social sciences. New York: Teachers College Press.

Shields, C. M. (2009). Transformative leadership: A call for difficult dialogue and courageous action in racialized contexts. International Studies in Educational Administration (Commonwealth Council for Educational Administration \& Management (CCEAM)), 37(3), 53-68.

Smith, L. (2016). Being a culturally proficient school leader is not an option, but rather a necessary and welcomed requirement. Leadership, 45(3), 17-19.

Smith, J. \& Osborn, M. (2008). Interpretative phenomenological analysis. In Smith, J. (Ed). Qualitative Psychology: A practical guide to Research Methods (pp. 5380). London, England: Sage Publications.

Snellman, K., Silva, J., \& Putnam, R. (2015). Inequity outside the classroom: Growing class differences in participation in extracurricular activities. VUE, 40, 7-14.

Southern Poverty Law Center. (2017). Teaching Tolerance. https://www.tolerance.org Ukpokodu, N. (2002). Breaking through preservice teachers' dispositions in a multicultural education course: A reflective practice. Multicultural Education, 9(3), 25-33. 
U.S. Census Bureau. (2010). United States quick facts. Retrieved from https://www.census.gov/quickfacts/fact/table/US/PST045216

U.S. Census Bureau. (2016). United States quick facts. Retrieved from https://www.census.gov/quickfacts/fact/table/US/RHI225216\#viewtop

Whiting, E. F., \& Cutri, R. M. (2015). Naming a personal "unearned" privilege: What pre-service teachers identify after a critical multicultural education course. Multicultural Perspectives, 17(1), 13-20. doi:10.1080/15210960.2014.984717

Wisconsin Department of Public Instruction. (2013). Pupil discrimination guidelines for athletes. Retrieved from https://dpi.wi.gov/sped/pupil-nondiscrimination Wisconsin Department of Public Instruction. (2016). Public school enrollment data. Retrieved from https://dpi.wi.gov/cst/data-collections/student/ises/publisheddata/excel

Wisconsin Department of Public Instruction. (2016). Wisconsin report cards. Retrieved from https://dpi.wi.gov/accountability/report-cards

Wisconsin Department of Public Instruction. (2017). Wisconsin report cards. https://dpi.wi.gov/accountability/report-cards

Zollers, N. J., Albert, L. R., \& Cochran-Smith, M. (2000). In pursuit of social justice: Collaborative research and practice in teacher education. Action in Teacher Research, 22(2), 1-14. 
Appendix A

Advisor Survey

As part of my doctoral work at the University of Missouri, I am conducting a survey that investigates advisor qualifications, resources for advisors, and content and curriculum for diversity related clubs. This survey is for my dissertation completion and will be stored on my computer. Your name will not be affiliated with the results of the survey. No one unaffiliated with the study will be able to see the surveys unless they have your written consent. Thank you for your participation in completing the following survey. It will take approximately 10 minutes, and your answers will remain confidential.

For purposes of this research study, diversity clubs are defined as any high school student club or organization whose goal is to promote inclusion and student knowledge about diversity. Diversity is defined as ethnicity, race, socioeconomic status, gender, exceptionalities, language, religion, and sexual orientation that are not represented in the majority population of this high school.

Quantitative Items

1. How many years have you taught? Please answer in the space provided.

2. How many years have you advised a diversity related club? Please answer in the space provided.

3. Which number below best represents how many collegiate classes you have taken centered on multicultural education?
a. Four or more classes
b. Three classes
c. Two classes
d. One class
e. None

4. Rate your level of agreement with this statement: I feel confident in my knowledge of multicultural education and diversity.
a. Strongly agree
b. Agree
c. Somewhat agree
d. Somewhat disagree
e. Disagree
f. Strongly disagree 
5. Which number best represents how you feel about the resources (funding, textbooks, supplies, space, etc.) provided to you at the onset of your accepting this position?
a. Very adequate amount
b. Adequate amount
c. Somewhat adequate amount
d. Somewhat inadequate amount
e. Inadequate
f. Very inadequate

6. Which number best represents how you feel about the professional development opportunities (conferences, in-service days, etc.) provided to you to aid in your leading of the club?
a. Very adequate amount
b. Adequate amount
c. Somewhat adequate amount
d. Somewhat inadequate amount
e. Inadequate
f. Very inadequate

Qualitative Items

1. Describe what, if any, curriculum provided to you when you began your diversity club advising role.

2. Describe what, if any, certification or training you have received that relates to your diversity club advising role.

3. Describe what, if any, resources were given to you when you began your diversity club advising role.

4. If you could make any changes to the organization of the diversity club, what would those changes be? 


\section{Appendix B}

\section{Principal Survey}

As part of my doctoral work at the University of Missouri, I am conducting a survey that investigates advisor qualifications, resources for advisors, and content and curriculum for diversity related clubs. This survey is for my dissertation completion and will be stored on my computer. Your name will not be affiliated with the results of the survey. No one unaffiliated with the study will be able to see the surveys unless they have your written consent. Thank you for your participation in completing the following survey. It will take approximately 10 minutes, and your answers will remain confidential.

For purposes of this research study, diversity clubs are defined as any high school student club or organization whose goal is to promote inclusion and student knowledge about diversity. Diversity is defined as ethnicity, race, socioeconomic status, gender, exceptionalities, language, religion, and sexual orientation that are not represented in the majority population of this high school.

1. What qualifications/certifications, if any, are considered when selecting diversity related club advisors? Please respond in the space provided.

2. To the best of your knowledge, what resources and professional development, if any, were provided to the club advisor?

3. Please describe how curriculum is created for extracurricular clubs and specifically, the diversity related club. 
Appendix C

Advisor Interview Protocol

Interviewee (Title and Name):

Interviewer:

Survey Section Used:

A: Interview Background

B: Advising

C: Demographics

Other Topics Discussed:

Documents Obtained:

Post Interview Comments

Introductory Protocol

To facilitate my note-taking, I would like to audiotape our conversations today. Please sign the release form. For your information, only researchers on the project will be privy to the tapes which will be eventually destroyed after they are transcribed. In addition, you must sign a form devised to meet our human subject requirements. Essentially, this document states that: (1) all information will be held confidential, (2) your participation is voluntary and you may stop at any time if you feel uncomfortable, and (3) we do not intend to inflict any harm. Thank you for your agreeing to participate.

I have planned this interview to last no longer than thirty minutes. During this time, I have several questions that I would like to cover. If time begins to run short, it may be necessary to interrupt you in order to push ahead and complete this line of questioning.

Introduction

You have been selected to speak with me today because you have been identified as someone who has a great deal to share about advising diversity related high school student 
organizations. My research project as a whole focuses on the diversity club advisor qualifications, resources for advisors, and content and curriculum of the club. My study does not aim to evaluate your techniques or experiences. Rather, I am trying to learn more about the organization of the club, and hopefully learn about advisor practices that help improve student inclusion in school.

Interview Questions

1. What curriculum would you like to incorporate into the diversity club? What would you need to be given in order to implement this curriculum/lessons?

2. What resources and professional development have you requested, if any? And how was that request handled?

3. Have you received curriculum or activity ideas from other diversity club advisors (even outside the district)? What methods have worked best for finding content for the club?

4. Survey results mentioned a lack of funding, both for the club and for an advisor stipend, as a current frustration. How does funding negatively or positively impact both your experience with the club and the students' experiences with the club?

5. What other important areas of advising preparedness and support can you tell me about? 
Appendix D

Principal Interview Protocol

Interviewee (Title and Name):

Interviewer:

Survey Section Used:

A: Interview Background

B: Advising

C: Demographics

Other Topics Discussed:

Documents Obtained:

Post Interview Comments

$\overline{\text { Introductory Protocol }}$

To facilitate my note-taking, I would like to audiotape our conversations today. Please sign the release form. For your information, only researchers on the project will be privy to the tapes which will be eventually destroyed after they are transcribed. In addition, you must sign a form devised to meet our human subject requirements. Essentially, this document states that: (1) all information will be held confidential, (2) your participation is voluntary and you may stop at any time if you feel uncomfortable, and (3) we do not intend to inflict any harm. Thank you for your agreeing to participate.

I have planned this interview to last no longer than thirty minutes. During this time, I have several questions that I would like to cover. If time begins to run short, it may be necessary to interrupt you in order to push ahead and complete this line of questioning.

Introduction

You have been selected to speak with me today because you have been identified as someone who has a great deal to share about diversity related high school student organizations. My research project as a whole focuses on the diversity club advisor qualifications, resources for advisors, and content and curriculum of the club. My study does not aim to evaluate your level of involvement with the club. Rather, I am trying to 
learn more about the organization of the club, and hopefully learn about advisor practices that help improve student inclusion in school.

Interview Questions

1. As a school leader, what curriculum do you hope to see implemented within a diversity club?

2. What resources and professional development related to diversity is traditionally offered to all staff each school year?

3. What is the process for an advisor request of professional development opportunities? Is there allocated funding for such requests?

4. How are resources disseminated amongst various high school extracurricular activities?

5. What other important areas of advising preparedness and support can you tell me about? 


\section{Appendix E \\ Recruitment Phone Script}

Hello,

My name is Brittany Parry and I am an EdD. Educational Leadership student at the University of Missouri. I am conducting a study to fulfill the graduation requirements of my program's dissertation process. The study concerns school leadership and advisors leading diversity related student clubs in a southwestern Wisconsin conference. There is very limited research on the necessary resources, content and curriculum, and teacher qualifications of diversity related clubs. This study will hopefully provide future school leaders and club advisors with some guidelines on how to get a club started or reform a club. I am looking for participants in this area because I teach locally at Cashton Public Schools and your conference has more diversity related clubs compared to surrounding conferences. I would be very grateful if you are willing to participate in my study. It is composed of two parts: a survey and an interview. The survey will take less than 10 minutes and can be completed electronically, and the interview will take place one time and last less than 30 minutes. Your participation would be completely confidential. The name of participants, each school district, and even the conference have been assigned pseudonyms to ensure confidentiality.

If you are interested, you will have the chance to find out more about the study before coming to any decision. You would be under no obligation to take part.

Would you be willing to participate in my study? If so, the following contact information can be utilized.

My study is supervised by Dr. Jeffrey Cornelius-White, and he can be contacted at JCornelius-White@missourisate.edu. I can be contacted at parry.brittany@cashton.k12.wi.us. The use of email to recruit participants for this study has been approved by the University of Missouri Institutional Review Board.

Thank you so much for your time! 
Appendix F

Recruitment Email

Hello,

My name is Brittany Parry and I am an EdD. Educational Leadership student at the University of Missouri. I had previously contacted you regarding participation in my study concerning school leadership and advisors leading diversity related student clubs in a southwestern Wisconsin conference. Again, all participant names, school district names, and the name of the conference have been assigned pseudonyms to ensure confidentiality. I would be very grateful if you are willing to participate in my study. The first part, the survey, will take place this month and will take less than 10 minutes. It will be distributed via email for the convenience of participants. The interview would follow up next month and would last less than 30 minutes. You would be able to select a location of your choosing at which the interview could take place.

With limited research on diversity clubs, I truly believe in the importance of identifying what practices are occurring in schools in regards to advisor training, club resourcing, and curriculum planning. If you are interested, please contact me at the address below. If you do so, you would be under no obligation to remain in the study if you desired to no longer participate.

My study is supervised by Dr. Jeffrey Cornelius-White, and he can be contacted at JCornelius-White@missourisate.edu. The use of email to recruit participants for this study has been approved by the University of Missouri Institutional Review Board.

Brittany Parry

parry.brittany@cashton.k12.wi.us 
Appendix G

Informed Consent

\title{
CONSENT Form to PARTICIPATE IN A RESEARCH STUDY
}

\author{
Researcher's Name(s): Brittany Parry, teacher at Cashton Public Schools \\ Project Number: \\ Project Title: Case Study of Southwestern Wisconsin Conference High School Diversity Clubs: \\ Advisor Qualifications, Club Resources, and Multicultural Curriculum
}

\section{INTRODUCTION}

This consent may contain words that you do not understand. Please ask the investigator or the study staff to explain any words or information that you do not clearly understand.

You are being asked to participate in a research study. This research is being conducted to gather data regarding advisor qualifications, resources provided to the advisor, and curriculum utilized within the diversity club. When you are invited to participate in research, you have the right to be informed about the study procedures so that you can decide whether you want to consent to participation. This form may contain words that you do not know. Please ask the researcher to explain any words or information that you do not understand.

You have the right to know what you will be asked to do so that you can decide whether or not to be in the study. Your participation is voluntary. You do not have to be in the study if you do not want to. You may refuse to be in the study and nothing will happen. If you do not want to continue to be in the study, you may stop at any time without penalty or loss of benefits to which you are otherwise entitled.

This research is funded by the researcher.

\section{WHY IS THIS STUDY BEING DONE?}

The purpose of this research is to organize research and provide guidelines in the following areas: advisor qualifications, resources for advisor, and content and curriculum for diversity related student organizations.

HOW MANY PEOPLE WILL BE IN THE STUDY? 
Advisors of diversity related student clubs and one building level administrator at each high school in the Southwestern Wisconsin Conference, which is approximately 25 participants.

\section{WHAT AM I BEING ASKED TO DO?}

Each participant be asked to respond to a survey distributed via email that will take approximately 10 minutes and participate in an interview that will last approximately 30 minutes.

\section{HOW LONG WILL I BE IN THE STUDY?}

This study will take place over the course of three months but the participants will only be actively participating in less than an hour of that time. The survey will take approximately 10 minutes and the interview will take 30 minutes or less. You can stop participating at any time without penalty.

\section{WHAT ARE THE BENEFITS OF BEING IN THE STUDY?}

Your experiences may help future diversity-related club advisors be prepared, establish curriculum, and set goals for their student organization. The further integration of multicultural education can lead to more cultural aware students which in turn can benefit society and the community as a whole.

\section{WHAT ARE THE RISKS OF BEING IN THE STUDY?}

There are no foreseeable risks to you for participating in the study. There are no risks to you if you choose not to participate. There also are no foreseeable risks to society or the local community as the data collected from this study will remain confidential and the actual name of each school district is replaced with a pseudonym.

\section{WHAT ARE THE COSTS OF BEING IN THE STUDY?}

There is no cost to you.

\section{WHAT OTHER OPTIONS ARE THERE?}

You have the option of not participating in this study, and will not be penalized for your decision.

\section{CONFIDENTIALITY}

Information you share will be stored in the researcher's hard drive. Participant names are not included in the study and the school districts involved have been assigned a 
pseudonym to preserve the confidentiality of all participants. The code key connecting district names to a specific school district will be kept in a separate, secure location. Information contained in my records cannot be given to anyone unaffiliated with the study in a form that could identify you without your written consent, except as required by law.

\section{WILL I BE COMPENSATED FOR PARTICIPATING IN THE STUDY?}

You will receive no payment for taking part in this study. However, a gift card will be given.

\section{WHAT ARE MY RIGHTS AS A PARTICIPANT?}

Participation in this study is voluntary. You do not have to participate in this study.

You will also be informed of any new information discovered during the course of this study that might influence your health, welfare, or willingness to be in this study.

\section{WHO DO I CONTACT IF I HAVE QUESTIONS, CONCERNS, OR COMPLAINTS?}

If you have any questions or concerns about the study, please contact me at parry.brittany@cashton.k12.wi.us or 573-647-6573. My study is supervised by Dr. Jeffrey Cornelius-White, and he can be contacted at JCornelius-

White@missourisate.edu.

\section{WHOM DO I CALL IF I HAVE QUESTIONS OR PROBLEMS?}

If you have any questions regarding your rights as a participant in this research and/or concerns about the study, or if you feel under any pressure to enroll or to continue to participate in this study, you may contact the University of Missouri Campus Institutional Review Board (which is a group of people who review the research studies to protect participants' rights) at (573) 882-9585 or umcresearchcirb@missouri.edu.

You may ask more questions about the study at any time. For questions about the study or a research-related injury, contact Brittany Parry or Dr. Jeffrey Cornelius-White at the emails above.

A copy of this Informed Consent form will be given to you before you participate in the research.

To protect the identity of participants, a signature is not necessary. Instead, verbal consent will be given from the participant. 


\section{VITA}

Brittany Cox Parry was born at Whiteman Air Force Base in Knob Noster, Missouri. Her father, Dave Cox, was a member of the Air Force and the family spent part of her childhood moving to various states, including Montana, Alabama, and California. She attended high school at Rolla High School and graduated valedictorian in 2007. She continued her education at William Woods University in Fulton, MO. and earned a Bachelor of Science in English Education and Bachelor of Science in Elementary Education in 2010. During 2011, she began her first teaching job at Nixa Public Schools while working on her master's program. She completed a Master of Science in Educational Administration K-12 degree in 2012 at Missouri State University. She began the University of Missouri's Statewide Cooperative Ed.D. Program in 2015. Defense of this dissertation will allow Brittany to graduate with her Ed.D. in May 2018. 